\title{
Mechanisms of Antifungal Drug Resistance
}

\author{
Leah E. Cowen ${ }^{1}$, Dominique Sanglard ${ }^{2}$, Susan J. Howard ${ }^{3}$, P. David Rogers ${ }^{4}$, \\ and David S. Perlin ${ }^{5}$ \\ ${ }^{1}$ Department of Molecular Genetics, University of Toronto, Toronto, Ontario M5S 1A8, Canada \\ ${ }^{2}$ University of Lausanne and University Hospital Center, Institute of Microbiology, 1011 Lausanne, Switzerland \\ ${ }^{3}$ University of Liverpool, Sherrington Building, Ashton Street, Liverpool L69 3GE, United Kingdom \\ ${ }^{4}$ College of Pharmacy, The University of Tennessee Health Science Center, Memphis, Tennessee 38163 \\ ${ }^{5}$ Public Health Research Institute, New Jersey Medical School, Rutgers, The State University of New Jersey, \\ Newark, New Jersey 07103 \\ Correspondence: perlinds@njms.rutgers.edu
}

\begin{abstract}
Antifungal therapy is a central component of patient management for acute and chronic mycoses. Yet, treatment choices are restricted because of the sparse number of antifungal drug classes. Clinical management of fungal diseases is further compromised by the emergence of antifungal drug resistance, which eliminates available drug classes as treatment options. Once considered a rare occurrence, antifungal drug resistance is on the rise in many high-risk medical centers. Most concerning is the evolution of multidrug- resistant organisms refractory to several different classes of antifungal agents, especially among common Candida species. The mechanisms responsible are mostly shared by both resistant strains displaying inherently reduced susceptibility and those acquiring resistance during therapy. The molecular mechanisms include altered drug affinity and target abundance, reduced intracellular drug levels caused by efflux pumps, and formation of biofilms. New insights into genetic factors regulating these mechanisms, as well as cellular factors important for stress adaptation, provide a foundation to better understand the emergence of antifungal drug resistance.
\end{abstract}

$T^{\mathrm{s}}$ he global burden of fungal infections is growing. More than 300 million people are believed to suffer from a serious fungal infection resulting in over 1,350,000 deaths (Brown et al. 2012). Fungal infections cause life-threatening acute diseases, like cryptococcosis and invasive aspergillosis, severe chronic diseases, such as allergic bronchopulmonary aspergillosis, or they may present less-threatening superficial infections, such as Candida vaginitis or oral can- didiasis (Warnock 2007). Most invasive fungal infections occur as a consequence of immune suppression that results from conditions, such as AIDS or from treatments, such as chemotherapy for cancer, immunosuppressive therapy for organ transplantation, and corticosteroid therapy for inflammation. More than $90 \%$ of reported fungal-associated deaths result from species belonging to three genera: Cryptococcus, Candida, and Aspergillus (Brown et al. 2012).

Editors: Arturo Casadevall, Aaron P. Mitchell, Judith Berman, Kyung J. Kwon-Chung, John R. Perfect, and Joseph Heitman Additional Perspectives on Human Fungal Pathogens available at www.perspectivesinmedicine.org

Copyright (C) 2015 Cold Spring Harbor Laboratory Press; all rights reserved; doi: 10.1101/cshperspect.a019752 Cite this article as Cold Spring Harb Perspect Med 2015;5:a019752 


\section{L.E. Cowen et al.}

Failure to treat effectively, because of inadequate or delayed diagnostics, may result in serious chronic illness or blindness or may be fatal. Recognition of the importance of fungal infections has led to a dramatic rise in the application of antifungal agents for the treatment and prevention of infection. Unfortunately, the treatment options are highly limited, as there are few chemical classes represented by existing antifungal drugs. The antifungal drug classes include: polyenes, azoles, allylamines, flucytosine, and echinocandins (Groll et al. 1998; Kathiravan et al. 2012). The azoles (e.g., fluconazole, voriconazole, and posaconazole) and allylamines (e.g., terbinafine) inhibit ergosterol biosynthesis, whereas polyenes (e.g., amphotericin B) bind to ergosterol in the plasma membrane, where they form large pores that disrupt cell function. Flucytosine (5-fluorocytosine) inhibits pyrimidine metabolism and DNA synthesis. Finally, the echinocandins (caspofungin, anidulafungin, and micafungin) are cell wall-active agents that inhibit the biosynthesis of $\beta-1,3-\mathrm{D}$ glucan, a major structural component of the fungal cell wall. The widespread use of antifungal agents is presumed to be a factor that promotes drug resistance (Antonovics et al. 2007; Cowen 2008). The emergence of acquired drug resistance among prevalent fungal pathogens restricts treatment options, which alters patient management. A greater understanding of mechanism-specific resistance and the biological factors that contribute to resistance emergence is critical to develop better therapeutics, and to improve diagnostics and intervention strategies that may overcome and prevent resistance. The detailed and complex biological nature of antifungal drug resistance mechanisms will be explored in this review with an emphasis on azoles and echinocandins, the two main classes of drugs used as first-line therapy.

\section{ASSESSING RESISTANCE FACTORS}

Clinical resistance refers to therapeutic failure in which a patient fails to respond to an antifungal drug following administration at a standard dose. The development of antifungal resistance is complex and depends on multiple host and microbial factors (White et al. 1998). Host immune status is a critical factor, as fungistatic drugs must work synergistically to control and clear an infection. Patients with severe immune dysfunction are more likely to fail therapy, as the antifungal drug must combat the infection without the benefit of an immune response (Ben-Ami et al. 2008). The presence of indwelling catheters, artificial heart valves, and other surgical devices may also contribute to refractory infections, as infecting organisms attach to these objects and establish biofilms that resist drug action (d'Enfert 2006; Ramage et al. 2009; Bonhomme and d'Enfert 2013). Appropriate therapy requires that each drug reach the site of infection at a concentration sufficient for antimicrobial action. The pharmacokinetics of many drugs is known, yet we still do not have a good understanding of drug penetration at all sites of infection. Thus, some microorganisms are exposed to drugs at suboptimal levels. This situation results in cells that persist during therapy and may form subclinical reservoirs seeding new infection. All of these factors contribute to microbial resistance, which refers to the selection of strains that can proliferate despite exposure to therapeutic levels of antifungals. Such strains contribute significantly to drug failures during therapy. Microbial resistance involves both primary resistant strains, which are inherently less susceptible to a given antifungal agent, and secondary resistant strains, which acquire a resistance attribute or trait in an otherwise susceptible strain following drug exposure. The molecular mechanisms involved in acquired resistance are often expressed at various levels in primary resistant strains (Fig. 1), and these will be explored in detail in this review.

\section{MOLECULAR MECHANISMS OF AZOLE RESISTANCE}

\section{Alterations in Ergosterol Biosynthetic Enzymes: Erg11 (Cyp51A) Substitutions}

Azole drugs target the ergosterol biosynthetic pathway. Ergosterol is a significant component of the fungal cell membrane; interruption of its synthesis allows accumulation of $14 \alpha$-methyl 
Drug Resistance Mechanisms

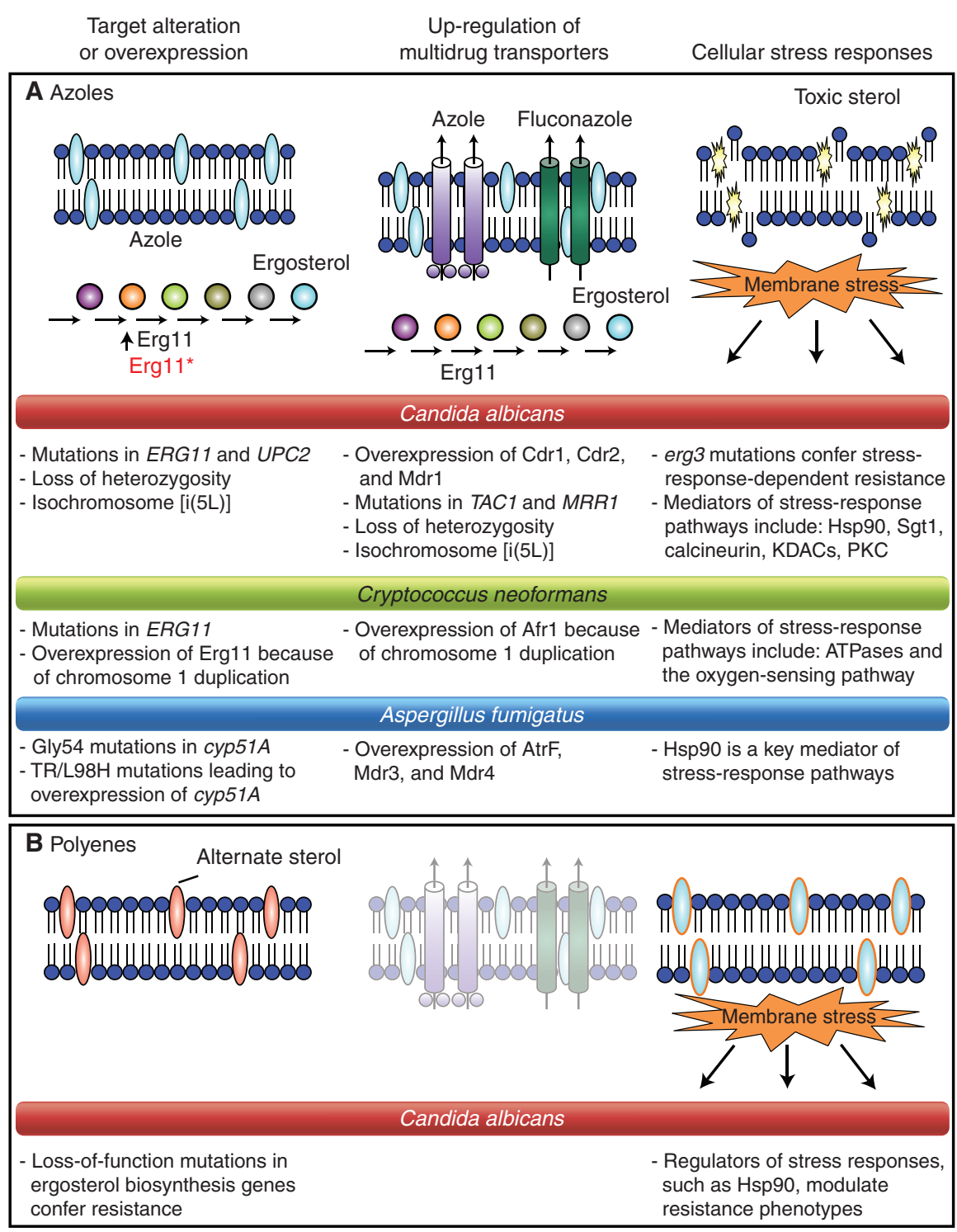

Figure 1. Mechanisms of resistance to antifungal drugs that target the cell membrane- the azoles and polyenes. (A) Azole resistance can emerge through multiple mechanisms including overexpression or alteration of the drug target, up-regulation of drug transporters, or cellular changes that reduce drug toxicity or enable tolerance of drug-induced stress. The colored circles indicate ergosterol biosynthesis intermediates. $(B)$ Polyene resistance generally involves depletion of the target ergosterol attributable to loss-of-function mutations in ergosterol biosynthetic genes. Bullet points describe resistance mechanisms for Candida albicans, Cryptococcus neoformans, and Aspergillus fumigatus. Dimmed images represent mechanisms that do not play a key role in resistance to the indicated drug class. (From Cowen 2008; adapted, with permission, from Macmillan (C) 2008.) 


\section{L.E. Cowen et al.}

sterols, which alters membrane stability, permeability, and the action of membrane-bound enzymes (White et al. 2002; Odds et al. 2003). The specific target of azoles is a cytochrome P450dependent enzyme lanosterol $14 \alpha$-demethylase (known as Erg11 in yeasts, which is homologous to Cyp51A in molds). Erg11/Cyp51A catalyze the oxidative removal of the $14 \alpha$-methyl group from lanosterol. Azole binding to the ferric iron moiety of the heme-binding site blocks the enzyme's natural substrate lanosterol, disrupting the biosynthetic pathway (Odds et al. 2003). Agents like doxycycline enhance the action of azoles like fluconazole presumably by depleting heme-associated iron (Fiori and Van Dijck 2012). Amino acid substitutions in the drug target that inhibit drug binding are a common azole-resistance mechanism in Candida; over 140 substitutions have been reported in resistant strains, many of which have an additive effect (Morio et al. 2010). Two of the most common alterations in C. albicans are R467K and G464S, near the heme-binding site (Casalinuovo et al. 2004; Morio et al. 2010). ERG11 mutations may play a lesser role in this species than increased drug efflux (Perea et al. 2001). Despite the potential for ERG11 point mutations to have a greater impact in haploid organisms (e.g., Candida glabrata) than in diploids (e.g., C. albicans), increased drug efflux is the most common resistance mechanism in C. glabrata as well (Borst et al. 2005; Sanguinetti et al. 2005). A limited number of ERG11 mutations have been reported in resistant strains of C. neoformans, including Y145F (Sionov et al. 2012) and G484S (Rodero 2003).

In A. fumigatus, target site alterations are the most commonly reported resistance mechanism, with over 30 cyp51A mutations identified (Howard and Arendrup 2011). Resistance can emerge in response to azole therapy (Verweij et al. 2007; Howard et al. 2009), and the causative mechanism can change over the course of infection (Chen et al. 2005; Howard et al. 2009). The most commonly reported Cyp51A substitutions that confer acquired resistance are at codons 54 and 220. The position and nature of the alteration within the protein structure influence cross-resistance within the drug class, with prox- imity to the heme-binding site affecting the binding of any azole drug (Xiao et al. 2004; Snelders et al. 2010; Fraczek et al. 2011). To date, all known mutations confer resistance to itraconazole, whereas resistance to voriconazole and/or posaconazole depend on the specific modification (Verweij et al. 2007, 2009; Howard and Arendrup 2011; van der Linden et al. 2011; Camps et al. 2012b). Resistance has also been identified in azole-naïve patients, which is environmentally derived and appears to be driven by the agricultural use of azoles (Snelders et al. 2012; Bowyer and Denning 2013; Verweij et al. 2013). These cases involved a Cyp51A substitution at position 98 (from leucine to histidine), and a 34-base tandem repeat (TR) in the cyp51A promoter, which leads to overexpression (Snelders et al. 2008). Both changes are required to confer resistance (Mellado et al. 2007). Notably, these resistant isolates can outcross with susceptible strains, suggesting the potential for resistance to transfer via the sexual cycle (Camps et al. 2012c). Strains bearing these alterations have emerged across Europe and beyond (Mortensen et al. 2010; Chowdhary et al. 2012). Further, a new resistance mutation selected from the environment, TR46/Y121F/T289A, is also being reported among patients in the Netherlands (van der Linden et al. 2013).

\section{Alterations in Ergosterol Biosynthetic Enzymes}

Overexpression of ERG11 is common among azole-resistant clinical isolates of C. albicans (White 1997; Franz et al. 1998; Perea et al. 2001). This contributes directly to resistance as an increase in target abundance requires more drug for inhibition (Franz et al. 1998), reducing susceptibility (Akins 2005). Multiple mechanisms account for ERG11 constitutive overexpression in azole-resistant clinical isolates. First, amplification of the ERG11 gene can occur by the formation of an isochromosome with two copies of the left arm of chromosome 5 (i(5L)), in which ERG11 resides, or by duplication of the entire chromosome (Selmecki et al. 2006). Second, activating mutations in the gene encoding the transcription factor Upc2 up-regulate most ergosterol biosynthesis genes (Silver et al. 2004; 
Drug Resistance Mechanisms

MacPherson et al. 2005; Flowers et al. 2012); disruption of C. albicans UPC2 causes hypersusceptibility to azoles.

Overexpression of ERG11 has also been reported for azole-resistant isolates of C. glabrata, Candida parapsilosis, Candida tropicalis, and Candida krusei (Barchiesi et al. 2000; Redding et al. 2002; Vandeputte et al. 2005; Rogers et al. 2006; Jiang et al. 2013). The mechanism for this overexpression or its contribution to azole resistance in these species remains largely unknown. Overexpression of Cyp51A in A. fumigatus (Cyp51) has been observed in two resistant clinical isolates from a patient who failed azole therapy (Arendrup et al. 2010). Whole genome sequencing of these isolates revealed a mutation in the CCAAT-binding transcription factor complex subunit HapE, leading to a P88L amino acid substitution, which conferred azole resistance and increased cyp51A expression (Camps et al. 2012a).

Inhibition of Erg3, a $\Delta^{5,6}$-desaturase, leads to a depletion of ergosterol and accumulation of $14 \alpha$-methylfecosterol, which allows continued growth in the presence of azole despite altered membrane composition (Lupetti et al. 2002). The erg 3 mutations are sufficient for azole resistance in Candida, although they are seldom associated with high-level resistance. The erg3 mutations are associated with cross-resistance to polyenes, likely caused by the depletion of the target ergosterol (White et al. 1998). To date, Erg3 alterations have not been associated with resistance in Aspergillus.

\section{Drug Uptake}

Drug action often requires import of the drug into the cell to reach the drug target. Some antifungal agents use specific permeases to enter cells. For example, 5-fluorocytosine uses permeases (FCA1, FCY2, FCY22, and FCY23) to enter C. albicans cells (Hope et al. 2004). Recently, it was shown that the antifungal peptide histatin 5 , as well as amine-containing substrates use the Dur31 permease in C. albicans (Mayer et al. 2012). The import of azoles into fungal cells is not completely understood, but may influence resistance. One recent study suggests that fluconazole enters C. albicans and other fungi by energy-independent facilitated diffusion, with azole import varying among $C$. albicans clinical isolates (Mansfield et al. 2010). The azole permease remains unknown.

\section{Drug Efflux}

A ubiquitous resistance mechanism is the activation of membrane-associated efflux pumps, which recognize diverse chemicals enabling multidrug resistance (MDR). In fungi, two different drug efflux systems modulate azole resistance, the ATP-binding cassette (ABC) superfamily and the major facilitator superfamily (MFS).

ABC proteins are ATP-dependent transporters that usually are arranged in a duplicated topology, comprising two transmembrane span (TMS) domains and two cytoplasmic nucleotide-binding domains (NBD) that catalyze ATP hydrolysis. The analysis of fungal pathogen genomes has identified varying numbers of $\mathrm{ABC}$ transporters with different topologies. C. albicans is predicted to contain $28 \mathrm{ABC}$ proteins (Prasad and Goffeau 2012), and C. glabrata approximately two-thirds of that number. Many more ABC proteins are found in A. fumigatus and $C$. neoformans (Lamping et al. 2010). There are several classes of fungal $\mathrm{ABC}$ transporters (Braun et al. 2005); however, only the pleiotropic drug resistance (PDR) class will be discussed here. In C. albicans, the PDR class comprises the major transporters involved in azole resistance including CDR1 (for Candida drug resistance) and CDR2, as well as other PDR-type transporters (Braun et al. 2005). Additional genes that encode the typical $\left(\mathrm{NBD}-\mathrm{TMS}_{6}\right)_{2}$ protein topology but that have not yet been implicated in resistance ( $C D R 3, C D R 4, C D R 11, S N Q 2)$ are also found in C. albicans. Up-regulation of both $C D R 1$ and CDR2 mediates azole resistance by enhanced drug efflux and reduced azole accumulation (Sanglard et al. 2009).

Specific ABC transporters have also been implicated in azole resistance in other fungal pathogens. These include $\mathrm{CgCdr} 1, \mathrm{CgCdr} 2$, and CgSnq2 in C. glabrata, and Afr1 in C. neoformans (Coleman and Mylonakis 2009). In 
L.E. Cowen et al.

A. fumigatus, decreased intracellular accumulation of itraconazole has been observed in itraconazole-resistant clinical isolates and laboratory-derived strains (Denning et al. 1997; Manavathu et al. 1999). Whereas the impact of specific transporters on azole resistance of $A$. fumigatus remains largely enigmatic, ABC transporter genes are up-regulated in response to azole exposure (AfuMDR1, AfuMDR2, and five genes designated $a b c A-E$ ) (Tobin et al. 1997; da Silva Ferreira et al. 2006), and in resistant clinical isolates (Slaven et al. 2002; Nascimento et al. 2003). AfuMDR1, renamed CDR1B, encodes the only transporter implicated directly in $A$. fumigatus azole resistance (Fraczek et al. 2013).

MFS transporters have multiple TMSs and use the electrochemical proton-motive force to power drug efflux. Their topology usually comprises 12 or 14 TMSs. MFS transporters are involved in MDR function by proton antiport and are classified in two groups: the drug: $\mathrm{H}^{+}$antiporter-1 (12 TMS) DHA1 family, and the drug: $\mathrm{H}^{+}$antiporter-2 (14 TMS) DHA2 family. The C. albicans genome sequence predicts 95 MFS transporters in 17 families (Gaur et al. 2008), but only one MFS, MDR1, has been implicated in azole resistance of $C$. albicans and Candida dubliniensis. MDR1 encodes a DHA1 MFS transporter that leads to enhanced azole efflux and azole resistance when overexpressed. Heterologous expression of MDR1 in Saccharomyces cerevisiae confers resistance to fluconazole but not to other azoles (Sanglard et al. 1995, 1996; Lamping et al. 2007). Expression of C. albicans FLU1 (for fluconazole resistance) in S. cerevisiae also confers fluconazole-specific efflux, although a similar role has not been identified in C. albicans (Calabrese et al. 2000). In A. fumigatus, AfuMDR3 encodes MFS transporter that is up-regulated in itraconazole-resistant mutants (Nascimento et al. 2003).

\section{MDR Regulation}

There have been considerable advances in understanding the transcriptional regulation of fungal multidrug transporters. As expected, general chromatin and transcriptional regulatory complexes influence expression of MDR genes. For example, the mediator complex serves as a transcriptional coactivator in all eukaryotes and influences MDR gene expression in S. cerevisiae and C. glabrata. The Gal11 subunit binds Pdr1 in and is required for up-regulation of Pdr1 targets (Thakur et al. 2008). The mediator complex can associate with other transcriptional coactivators. The transcriptional adaptor Ada2, which is part of the SAGA coactivator complex, binds to both CDR1 and MDR1 promoters in C. albicans (Sellam et al. 2009a). The complex landscape of specific cis- and transregulatory elements that control expression of MDR genes is described below.

\section{Cis-Acting Elements}

Cis-acting elements regulating $C D R 1, C D R 2$, and $M D R 1$ were first identified in C. albicans. The promoters of CDR1 and CDR2 contain common drug responsive element (DRE) sequences that are required for transcriptional up-regulation in response to inducers (steroids, fluphenazine) or in azole-resistant strains (de Micheli et al. 2002). MDR1 cis-acting elements can have complex arrangements that differ depending on the inducer. For example, a benomyl response element (BRE, -296 to -260 with respect to the first ATG) is required for benomyldependent MDR1 up-regulation and an $\mathrm{H}_{2} \mathrm{O}_{2}$ response element ( $\mathrm{HRE},-561$ to -520 ) is required for $\mathrm{H}_{2} \mathrm{O}_{2}$-dependent MDR1 up-regulation (Rognon et al. 2006). The BRE contains a perfect match to the consensus binding sequence of $\mathrm{Mcm} 1$, which regulates $M D R 1$ expression (Riggle and Kumamoto 2006).

In C. glabrata, ABC-transporter regulation is more similar to that in S. cerevisiae (Paul et al. 2011). Pleiotropic drug responsive elements (PDREs) present in CgCDR1, CgCDR2, and CgSNQ2 are structurally similar to those in $S$. cerevisiae (Sanglard et al. 1999; Torelli et al. 2008). PDREs of $C g C D R 1$ are necessary for high-level $C D R 1$ expression in mitochondrial mutants (Paul et al. 2011).

\section{Trans-Acting Elements}

The first major transcription factor important for regulating efflux activity was TAC1 (for tran- 
scriptional activator of $C D R$ genes), a member of the $\mathrm{Zn}_{2} \mathrm{Cys}_{6}$ transcription factor family from C. albicans. TAC1 is critical for the up-regulation of CDR1 and CDR2 in response to drugs or in clinical azole-resistant isolates. Constitutive upregulation of $C D R 1$ and $C D R 2$ can be attributed to gain-of-function (GOF) mutations in different domains of TAC1 (Coste et al. 2004, 2006). Nineteen different TAC1 mutations have been confirmed as GOF, whereas others remain candidates (Coste et al. 2009; Siikala et al. 2010; Sanglard 2011). The TAC1 regulon was further elucidated by genome-wide transcriptional profiling and DNA occupancy analysis of Tac1 (Liu et al. 2007), demonstrating that Tac1 binds to the DRE of CDR1 and CDR2, likely via a consensus-binding motif ( $\left.\mathrm{CGGN}_{4} \mathrm{CGG}\right)$. Recently, another CDR1 regulator was discovered by systematic overexpression of modified $\mathrm{Zn}_{2} \mathrm{Cys}_{6}$ genes; MRR2 (orf19.6182) is required for the basal expression of CDR1; however, it does not regulate CDR2 (Schillig and Morschhauser 2013).

The C. glabrata orthologs of CDR1 and $C D R 2$ are regulated by the transcriptional activator, CgPdr1, identified based on homology with S. cerevisiae Pdr1 and Pdr3, key transcriptional regulators of multidrug resistance (Vermitsky and Edlind 2004). CgPdr1 binds to the PDRE consensus in CgCDR1 (Paul et al. 2011). GOF mutations hyperactivate $\mathrm{CgPdr} 1$, resulting in up-regulation of target genes, including the $\mathrm{ABC}$ transporters involved in azole resistance (Vermitsky and Edlind 2004; Tsai et al. 2006; Vermitsky et al. 2006; Ferrari et al. 2009; Caudle et al. 2011). Fifty-eight distinct GOF mutations have been identified at 51 positions in $C g P D R 1$ alleles from clinical azole-resistant isolates (Ferrari et al. 2009). Notably, only a few genes were commonly regulated by the GOF mutations, suggesting complex interactions of CgPDR1 with transcriptional machinery (Tsai et al. 2010; Caudle et al. 2011; Ferrari et al. 2011b). Consistent with this, the Gal11p/MED15 subunit of the mediator coactivator and the KIX domain interact with $\mathrm{CgPdr} 1$, which is critical for MDR regulation (Monk and Goffeau 2008; Thakur et al. 2008; Naar and Thakur 2009).
The other important regulator of multidrug resistance in C. albicans is the $\mathrm{Zn}_{2} \mathrm{Cys}_{6}$ transcription factor Mrr1 (for multidrug-resistance regulator 1), which regulates the MFS transporter gene MDR1. MRR1 was discovered by genome-wide transcriptional analysis of $C$. albicans isolates that up-regulated $M D R 1$. Deletion of MRR1 in clinical strains blocked MDR1 up-regulation (Morschhauser et al. 2007). Fifteen different MRR1 GOF mutations have been reported (Sanglard 2011; Eddouzi et al. 2013), causing constitutive up-regulation of MDR1 (Dunkel et al. 2008). Genome-wide transcriptional studies using clinical strains revealed a core set of 14 genes involved in diverse functions that are up-regulated in isolates carrying $M R R 1$ GOF mutations (Morschhauser et al. 2007). Genome-wide in vivo occupancy studies of a hyperactive form of Mrr1 identified 701 binding sites and a putative binding motif, DCSGHD (Schubert et al. 2011), which was also found in MDR1 regulatory regions (Hiller et al. 2006; Rognon et al. 2006).

Besides Tac1/Mrr1 and CgPdr1, additional positive regulators of MDR have been reported in C. albicans. Cap1 is a basic region leucine zipper (bZIP) transcription factor, which binds to the MDR1 promoter and regulates MDR1 expression in oxidative stress conditions (Alarco and Raymond 1999; Znaidi et al. 2009). Mcm1 also binds to the $M D R 1$ promoter at the binding consensus motif $\left[\mathrm{CC}(\mathrm{A} / \mathrm{T})_{6} \mathrm{GG}\right]$ (Riggle and Kumamoto 2006; Lavoie et al. 2008). There are distinct requirements for $\mathrm{Mcm} 1$ in the activation of MDR1; Mcm1 is dispensable for induction of MDR1 in response to oxidative stress or CAP1 gain-of-function mutation, but is required for full induction of $M D R 1$ in response to benomyl or MRR1 gain-of-function mutation (Mogavero et al. 2011). Ndt80 is similar to a meiosis-specific transcription factor in $S$. cerevisiae, but regulates $C D R 1$ expression (Chen et al. 2004). Ndt80 also binds other transporter genes, including $C D R 2, C D R 4$, orf19.4531 MDR1, and FLU1 (Sellam et al. 2009b) as well as genes, such as ERG11, that encode ergosterol biosynthesis enzymes.

There are additional negative regulators of MDR. C. albicans REP1 (for regulator of efflux 


\section{L.E. Cowen et al.}

pump 1) has similarity with NDT80, and its deletion causes up-regulation of MDR1 expression in response to 4 -nitroquinoline- $N$-oxide (Chen et al. 2009). FCR1 (for fluconazole resistance) was cloned in a $S$. cerevisiae screen for azole resistance (Talibi and Raymond 1999). However, C. albicans FCR1 appears to have a different function, as deletion of CaFCR1 enables the emergence of azole resistance (Shen et al. 2007). In C. glabrata, the $\mathrm{Zn}_{2} \mathrm{Cys}_{6}$ transcription factor Stb5 represses expression of $\mathrm{ABC}$ transporter genes including $C g C D R 1$ and CgCDR2 (Noble et al. 2013). In S. cerevisiae Sbt5 and Pdr1 form a heterodimer (Akache et al. 2004), as do Pdr1 and Pdr3 (Mamnun et al. 2002).

\section{Chromosomal Abnormalities}

Multiple genomic alterations have been associated with azole resistance, including loss of heterozygosity ( $\mathrm{LOH}$ ) of specific genomic regions, increase of chromosome copy number, as well as segmental or chromosomal aneuploidies. $\mathrm{LOH}$ is common for regions containing azoleresistance determinants including ERG11, TAC1, or MRR1. Analysis of sequential C. albicans isolates that evolved resistance in patients revealed that mutations in these genes often arise in the heterozygous state and become homozygous by LOH (Coste et al. 2007; Selmecki et al. 2010). Larger-scale changes of chromosomes harboring azole-resistance determinants have also been associated with resistance in C. albicans. ERG11 and TAC1 reside on the left arm of chromosome 5, thus the formation of isochromosome $\mathrm{i}(5 \mathrm{~L})$ increases their copy number and confers resistance (Selmecki et al. 2006). Variant forms of $i(5 \mathrm{~L})$ exist, including one that incorporates the region of the chromosome 3 right arm that contains CDR1 and MRR1 (Selmecki et al. 2009), thus facilitating resistance development. The prevalence of aneuploidies in azole-resistant isolates raised the question of whether azole exposure simply selects for the more resistant aneuploid variants or whether azole exposure contributes to the generation of aneuploidies. Consistent with the latter possibility, azole exposure was found to cause aberrant cell cycle regulation in C. albicans with a tetraploid intermediate preceding aneuploidy formation (Harrison et al. 2014).

Chromosomal alterations have also been associated with resistance in C. glabrata and C. neoformans. C. glabrata can acquire azole resistance by increasing the copy number of ERG11 (Marichal et al. 1997). Further, the formation of segmental aneuploidies and novel chromosome configurations has been identified in azole-resistant isolates of C. glabrata (Poláková et al. 2009). For C. neoformans, azole resistance is associated with specific chromosome alterations, especially disomies of chromosomes 1 and 4 . Chromosome 1 contains two azole-resistance determinants, the azole target gene ERG11 and ABC transporter gene AFR1 (Sionov et al. 2010). Alteration in copy number of these chromosomes also relates to the phenomenon of heteroresistance, in which subpopulations within the same clone vary in resistance based on the frequent loss and gain of chromosomes in response to selection (Sionov et al. 2010, 2013).

\section{Mitochondrial Defects}

The relationship between mitochondrial dysfunction and azole resistance is based mainly on the observation that both $S$. cerevisiae and C. glabrata can survive partial or complete loss of mitochondrial DNA (formation of "petite" mutants) (Gulshan and Moye-Rowley 2007). Petite mutants are intrinsically resistant to azoles owing to up-regulation of transcriptional activators (PDR3 in S. cerevisiae; CgPDR1 in $C$. glabrata) and their target genes (Ferrari et al. 2011a). For C. glabrata, in vitro exposure to fluconazole can give rise to mitochondrial mutants at high frequency (Sanglard et al. 2001; Brun et al. 2003, 2004). Selection of these mutants in the clinical context is much less frequent (Bouchara et al. 2000; Ferrari et al. 2011a). Although some C. glabrata clinical isolates with mitochondrial dysfunction do not show fitness defects compared with wild-type parents in a mouse infection model (Ferrari et al. 2011a), other C. glabrata petite mutants are avirulent (Singh et al. 2009; Singh-Babak et al. 2012). C. albicans cannot undergo loss of mitochon- 
Drug Resistance Mechanisms

drial DNA and therefore is considered a "petitenegative" species. However, pharmacological inhibition of mitochondrial complexes involved in respiration and energy production results in higher susceptibility to azoles in this species (Sun et al. 2013). The findings that mitochondrial defects are associated with azole resistance in C. glabrata, but susceptibility in C. albicans, suggests complex functional relationships between the azoles activity and mitochondrial function in fungal pathogens.

\section{Resistance Acquisition through Multiple Mechanisms}

The emergence of azole resistance is often associated with stepwise increases in resistance over time. This has been documented in sequential isolates from patients before and after antifungal treatment (Sanglard et al. 1995, 1998a,b; White et al. 1998; Lopez-Ribot et al. 1999; Marr et al. 2001; Perea et al. 2001; Martinez et al. 2002). Stepwise acquisition of resistance involves multiple mechanisms. Molecular epidemiology of azole resistance in a large population of $C$. albicans suggests that CDR1/CDR2 up-regulation is more prevalent than ERG11 or $M D R 1$ up-regulation, with combinations of $C D R 1 / C D R 2$ up-regulation and ERG11 alterations as the most common (Goldman et al. 2004; Park and Perlin 2005; Coste et al. 2007; Siikala et al. 2010; Flowers et al. 2012). Although $C D R 1 / C D R 2$ and $M D R 1$ up-regulation can be explained by TAC1 and MRR1 GOF mutations, ERG11 up-regulation is not always associated with UPC2 GOF mutations, implicating additional regulators (Flowers et al. 2012). The contribution of individual mutations to resistance of a clinical isolate was recently dissected by sequential replacement of mutated alleles (TAC1/ERG11) with wild-type alleles, confirming the functional importance of each mutation (MacCallum et al. 2010). In addition to the sequential acquisition of mutations, larger-scale genomic alterations, such as $\mathrm{LOH}$ and changes in copy number of azole-resistance genes, can occur during the evolution of high-level azole resistance in clinical isolates (Selmecki et al. 2006). In contrast to the prevalence of stepwise increases in resistance caused by multiple mechanisms in C. albicans, high-level resistance of C. glabrata often occurs in a single step via GOF mutations in CgPDR1 (Ferrari et al. 2009).

\section{Biofilms}

Biofilms are one of the most prevalent forms of microbial growth in nature, and Candida species are among the most common etiologic agents of biofilm infections (Kumamoto 2002; Ramage et al. 2009), although other yeasts and filamentous fungi are important biofilm producers as well (Ramage et al. 2009). Biofilms display an organized three-dimensional structure comprised of a dense network of yeast and filamentous cells embedded in an exopolymeric matrix consisting of carbohydrates, proteins, and nucleic acids. The matrix is a major feature that distinguishes biofilms from planktonic cells. Candida biofilms are intrinsically resistant to azoles, and the mechanisms are multifactorial, involving induction of drug efflux transporters and drug sequestration within the extensive matrix structure (Kumamoto 2002; Mukherjee et al. 2003; Chandra et al. 2005; Ramage et al. 2009; Fanning and Mitchell 2012). As with planktonic C. albicans, active drug efflux can be induced by up-regulation of $C D R$ and $M D R$ genes (Ramage et al. 2002; Mukherjee et al. 2003). However, drug sequestration within the extracellular matrix is the largest determinant of the multidrug-resistance phenotype (Nett et al. 2010a). Matrix production is highly regulated and is a key resistance factor for Candida spp., including C. albicans, C. glabrata, C. parapsilosis, C. tropicalis, and C. dubliniensis (Silva et al. 2009). A key biofilm constituent is $\beta$-1,3-glucan, which is produced by glucan synthase. Downstream components of the yeast PKC pathway, including Smil, Rlm1, Rho1, and Fsk1, regulate $\beta$-1,3-glucan biosynthesis and biofilm matrix production (Nett et al. 2010a,b, 2011; Desai et al. 2013). Other cellular proteins, such as the transcription factor Zap1, alcohol dehydrogenases Adh5, Csh1, and Ifd6, as well as glucoamylases, $\mathrm{CaGca} 1$ and $\mathrm{CaGca} 2$, also affect matrix production and resistance phenotypes (Nobile et al. 2009). 
L.E. Cowen et al.

\section{Hsp90 and Related Factors}

Cellular stress-response circuitry provides a critical strategy for fungi to survive the cell membrane stress induced by exposure to azoles. This circuitry enables basal tolerance to azoles, as well as resistance that was acquired by diverse mechanisms (Cowen and Steinbach 2008; Shapiro et al. 2011). A leading example of a global cellular regulator that governs stress responses crucial for azole tolerance and resistance is the molecular chaperone Hsp90 (Cowen 2008, 2009, 2013). Hsp90 is a conserved and essential chaperone that regulates cellular signaling by stabilizing a myriad of client proteins, many of which are signal transducers (Taipale et al. 2010). Compromise of Hsp90 function genetically or pharmacologically reduces tolerance of Candida species to azoles (Cowen et al. 2009). Inhibition of Hsp90 can also block the evolution of azole resistance, and abrogate resistance caused by the loss of function of Erg3 or resistance that evolved in a human host by multiple mechanisms (Cowen and Lindquist 2005; Cowen et al. 2006). In addition to its role in azole resistance of planktonic cells, Hsp90 also regulates azole resistance of Candida biofilms (Robbins et al. 2011). The circuitry through which Hsp90 regulates drug resistance is best studied in C. albicans planktonic cells, where the key client proteins are calcineurin and Mkc1. Calcineurin is a protein phosphatase that is required to survive the cell membrane stress induced by azoles (Cruz et al. 2002; Sanglard et al. 2003; Steinbach et al. 2007). Hsp90 physically interacts with and stabilizes the catalytic subunit of calcineurin, such that depletion of Hsp90 leads to depletion of calcineurin (Singh et al. 2009). Hsp90 also stabilizes the terminal mitogen activated protein kinase (MAPK) of the cell wall integrity pathway, $\mathrm{Mkc1}$, thereby modulating additional responses to azole-induced cell membrane stress (LaFayette et al. 2010). Although calcineurin and $\mathrm{Mkcl}$ are also implicated in azole resistance of $C$. albicans biofilms, depletion of Hsp90 does not affect their stability in this cellular state (Robbins et al. 2011). Within biofilms, depletion of Hsp90 reduces matrix glucan levels, thereby reducing azole resistance
(Robbins et al. 2011). Inhibition of Hsp90 function with drugs that are well tolerated in humans enhances the efficacy of azoles against resistant Candida strains in infection models including the invertebrate Galleria mellonella, as well as the rat central venous catheter model of biofilm infection, in which the infection and drug delivery are localized (Cowen et al. 2009; Robbins et al. 2011). Toxicity of Hsp90 inhibitors has been observed when in the context of mouse models of disseminated Candida infection, motivating the search for fungal selective Hsp90 inhibitors or inhibitors that target components of the Hsp90 chaperone network that are more divergent between pathogen and host (Cowen 2009).

Recent studies have revealed upstream regulators of Hsp90 function with a profound impact on azole resistance. Hsp90 function is regulated by cochaperones and a complex code of posttranslational modifications (Taipale et al. 2010). The first analysis of an Hsp90 cochaperone in a fungal pathogen revealed that Sgt1 physically interacts with Hsp90 in C. albicans, and that depletion of Sgt1 abrogates azole tolerance and resistance (Shapiro et al. 2012). Hsp90 function was also found to be regulated by acetylation such that pharmacological inhibition of lysine deacylases phenocopies inhibition of Hsp90, blocking the evolution of azole resistance and reducing resistance of $C$. albicans that evolved in a human host (Robbins et al. 2012). Regulation of Hsp90 function by acetylation is conserved in A. fumgiatus, in which the key residue for azole and echinocandin resistance is K27 (Lamoth et al. 2014b). In S. cerevisiae, the key lysine deacetylases that modulate Hsp90 function are Hdal and Rpd3 (Robbins et al. 2012), although the relevant players remain enigmatic in other fungi.

\section{mRNA Stability}

An additional mechanism that contributes to azole resistance is enhanced mRNA stability. This has been studied mostly in the context of CDR1 expression, encoding a multidrug efflux transporter in C. albicans. Analysis of two matched pairs of azole-susceptible and resistant 
isolates revealed that the half-life of $C D R 1$ mRNA was threefold higher in resistant isolates compared with their susceptible counterparts (Manoharlal et al. 2008). The polyA tail of CDR1 mRNA was also $~ 35 \%-50 \%$ hyperadenylated in the resistant isolates (Manoharlal et al. 2008). mRNA adenylation is controlled by poly(A) polymerase (Pap1), which is encoded by two distinct alleles in close proximity to the mating type locus. Whereas the susceptible isolates were heterozygous for $P A P 1$, the resistant isolates were homozygous for the PAP1- $\alpha$ allele (Manoharlal et al. 2010). Pap1-a has a repressive effect on CDR1 transcript polyadenylation and stability, such that PAP1- $\alpha$ homozygosity contributes to azole resistance (Manoharlal et al. 2010). Together, this reinforces the importance elevated of Cdr1 levels for drug resistance, which can be achieved by transcriptional up-regulation as well as enhanced mRNA stability.

\section{MECHANISMS OF ECHINOCANDIN RESISTANCE}

\section{FKS Mechanism of Resistance}

Echinocandin resistance resulting in clinical failures is conferred by limited amino acid substitutions in the Fks subunits of glucan synthase (Perlin 2011a). Unlike azole antifungal agents, resistance to echinocandins is largely unaffected by multidrug transporters (Bachmann et al. 2003; Niimi et al. 2006); this is consistent with the model that echinocandins may function at the outer membrane (Healey et al. 2012; Johnson and Edlind 2012). In C. albicans and most other Candida spp., resistance mutations occur in two highly conserved "hot-spot" regions of FKS1 (Garcia-Effron et al. 2009b; Katiyar and Edlind 2009; Johnson et al. 2011), encompassing residues Phe641-Pro649 and Arg1361 (C. albicans equivalent) (Park et al. 2005), and/or equivalent regions of FKS2 in C. glabrata (Katiyar et al. 2006; Garcia-Effron et al. 2009a). The amino acid substitutions decrease sensitivity of glucan synthase to drug by 50 - to 3000 -fold (Katiyar et al. 2006; Garcia-Effron et al. 2009a,b), and elevate MIC values 5- to 100-fold. For C. albicans, amino acid changes at Ser645 are the most frequent and cause the most pronounced resistance phenotype (Garcia-Effron et al. 2009a,b; Perlin 2011a,b). In C. glabrata, comparable mutations conferring resistance occur in both FKS1 and FKS2. Changes at Fks2 Ser663 (equivalent to C. albicans Ser645) in Fks2 are the most prominent amino acid substitution (>50\%) (Garcia-Effron et al. 2009a). Other substitutions encountered in clinical failures include Ser629 in Fks1 and Phe659 in Fks2. Consistent with the clinical experience, substitutions at positions Ser641 and Ser645 in C. albicans and equivalent positions in C. glabrata show poor drug response in pharmacodynamic studies of murine infection models (Howard et al. 2011; Slater et al. 2011; Wiederhold et al. 2011; Arendrup et al. 2012). Other hot-spot mutations may confer phenotypic resistance, but escalating drug doses are more effective against resistant strains harboring such mutations (Arendrup et al. 2012). The echinocandin-resistance level conferred by hot-spot mutations in FKS1 or FKS2 may also depend on the relative expression of these genes, which can vary more than 20-fold (Garcia-Effron et al. 2009a; Katiyar et al. 2012). FKS2 expression is calcineurin dependent and down-regulated by FK506 (tacrolimus) (Eng et al. 1994). Resistance conferred by FKS2 but not FKS1 is reversed following treatment with the calcineurin inhibitor FK506 (Katiyar et al. 2012). Recently, a third hot-spot region was identified that confers in vitro resistance, and is defined by W695 in S. cerevisiae Fks1 and equivalent residues F695 and W760 from Scedosporium species and Schizosaccharomyces pombe, respectively; the equivalent substitution in C. glabrata also has a role in resistance (Johnson et al. 2011). Notably, amino acid substitutions in Fks1 of C. albicans often confer reduced fitness (Garcia-Effron et al. 2009a; Katiyar et al. 2012), as they are associated with a decreased catalytic reaction rate for glucan biosynthesis (Garcia-Effron et al. 2009a,b), resulting in altered cell wall morphology (Ben-Ami et al. 2011). A consequence of reduced fitness is that echinocandinresistant strains compete poorly with their wildtype counterpart (Ben-Ami et al. 2011), which may explain why resistant strains are rarely transmitted between patients. 
L.E. Cowen et al.

\section{Hot-Spot Polymorphisms and Inherent Reduced Susceptibility}

The C. parapsilosis complex (C. parapsilosis sensu stricto, Candida orthopsilosis, and Candida metapsilosis) and Candida guilliermondii display higher echinocandin MIC values relative to other susceptible Candida species (Pfaller et al. 2008a, 2010; Tortorano et al. 2013). The mechanism underlying reduced echinocandin susceptibility involves naturally occurring polymorphisms in FKS hot-spot regions (GarciaEffron et al. 2008). In the C. parapsilosis complex, the highly conserved Pro660 at the distal edge of hot spot 1 is present as an alanine. Kinetic inhibition studies showed that glucan synthase from the C. parapsilosis group was $1-2 \operatorname{logs}$ less sensitive to echinocandins than typical enzymes from C. albicans. Strains of C. albicans and C. glabrata, as well as engineered strains of S. cerevisiae that harbor amino acid substitutions at this position show decreases in target enzyme sensitivity and increased MIC values (Garcia-Effron et al. 2008). Overall, it appears that naturally occurring Fks1 polymorphisms in hot-spot regions of non-albicans Candida spp. and other fungi contribute to reduced susceptibility (Fig. 2).

\section{Biofilms}

As with azole resistance, the glucan matrix sequesters echinocandin drugs, preventing them from reaching the cell membrane. Disruption of this process by genetic or chemical modification of $\beta$-1,3-glucan synthase decreases drug sequestration in the matrix, rendering biofilms susceptible to antifungal agents (Desai et al. 2013). This mechanism accounts for a large fraction of the drug-resistance phenotype during biofilm growth (Nett et al. 2011), and contributes to the formation of a subpopulation of persister cells that are drug resistant. The cell wall biosynthesis protein Smil has been implicated in biofilm matrix glucan production and the development of drug resistance; it acts through the transcription factor Rlm1 and glucan synthase Fks1. Smil functions in conjunction with Rlm1 and Fks1 to produce drug-sequestering biofilm $\beta$-glucan (Desai et al. 2013).

\section{Adaptive Cellular Factors}

Fungi possess adaptive cellular factors that confer protection against cellular stresses, such as those encountered on inhibition of glucan synthase by echinocandins (Perlin 2007; Walker et al. 2010). These stress adaptation responses may result in elevated in vitro MIC values to echinocandins, but they are not typically associated with clinical failures (Kartsonis et al. 2005; Pfaller et al. 2008b). However, drug tolerance may be an important intermediate stage for development of FKS-mediated resistance as it enables a larger population of surviving cells in response to drug exposure that can respond to selection and evolve resistance. Consistent with this model, fungal stress tolerance pathways including cell wall integrity, protein kinase $\mathrm{C}(\mathrm{PKC}), \mathrm{Ca}^{2+} /$ calcineurin/Crz1, and high osmolarity glycerol (HOG) cascades enable survival of echinocandin-induced stress by controlling compensatory up-regulation of chitin synthesis (Munro et al. 2007; Walker et al. 2008), and constitutive up-regulation of chitin is associated with echinocandin resistance caused by FKS1 mutations (Walker et al. 2013). Also, changes in the cell membrane can alter echinocandin action. For some laboratory and clinical isolates, defects in sphingolipid biosynthesis lead to a mixed phenotype in which strains are resistant to caspofungin and hypersensitive to micafungin (Healey et al. 2011, 2012); the opposing effects on susceptibility to the two echinocandins led to the model that the altered sphingolipid composition of the plasma membrane weakens the interaction between Fks and caspofungin while strengthening the interaction between Fks and micafungin.

\section{Chitin Synthesis}

As alluded to above, increased chitin synthesis has emerged as an important mechanism enabling fungal cells to survive echinocandin exposure, with implications for resistance. Exposure of C. albicans to low levels of echinocandins 


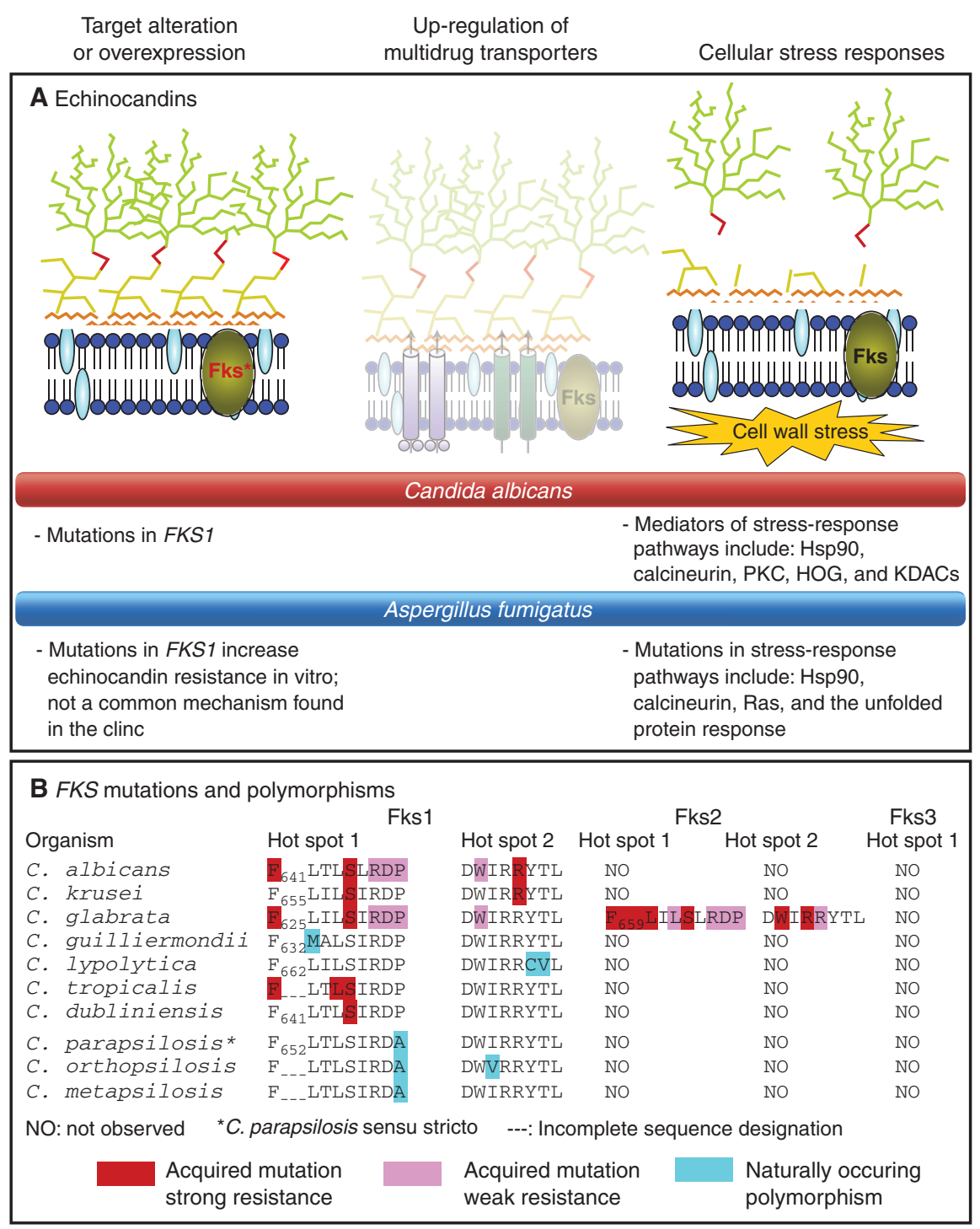

Figure 2. Mechanisms of resistance to antifungal drugs that target the cell wall-the echinocandins. $(A)$ Mutations in FKS1, which encodes the catalytic subunit of the echinocandin target $(1,3)-\beta$-D-glucan synthase, are the most prevalent cause of echinocandin resistance. Cellular stress-response pathways modulate resistance phenotypes. Bullet points describe resistance mechanisms for C. albicans and A. fumigatus. Dimmed images represent mechanisms that do not play a key role in resistance. $(B)$ Distribution of acquired mutations and naturally occurring polymorphisms within FKS genes conferring reduced echinocandin susceptibility. (From Cowen 2008; adapted, with permission, from Macmillan (C) 2008, and from Perlin 2007; adapted, with permission, from Elsevier (C) 2007.)

induces chitin synthase gene expression, and leads to elevated chitin content and reduced echinocandin efficacy (Walker et al. 2008). This compensatory increase in chitin is coordinated by the PKC, HOG, and calcineurin signaling pathways (Munro et al. 2007). Activation of two of the chitin synthases, Chs2 and Chs8, enables survival of otherwise lethal doses of echinocandins (Walker et al. 2008). Elevated chitin content following echinocandin exposure is also observed in C. tropicalis, C. parapsilosis, and Candida guillermondii, in addition 


\section{L.E. Cowen et al.}

to some C. krusei isolates (Walker et al. 2013). In C. glabrata, the terminal MAPK of the PKC signaling pathway, Slt2, controls chitin increase in response to echinocandins (Cota et al. 2008). Echinocandin resistance attributed to mutations in FKS1 is associated with elevated chitin levels and the absence of compensatory increases in chitin on echinocandin exposure (Walker et al. 2013). Increased cell wall chitin also confers reduced susceptibility to echinocandins in a mouse model of systemic C. albicans infection (Lee et al. 2012). The importance of chitin synthesis for surviving echinocandin exposure extends beyond Candida species to Aspergillus. In A. fumigatus, deletion of chitin synthesis genes CSMA and CSMB has little impact on overall cell wall chitin content, but leads to disorganized cell wall structure and increased susceptibility to echinocandins (Jimenez-Ortigosa et al. 2012). Consistent with the importance for chitin synthesis in responses to echinocandins, chitin synthesis inhibitors have synergistic activity with echinocandins (Walker et al. 2008). These responses also have been invoked to explain the "paradoxical growth effect," which refers to growth of echinocandin susceptible fungi at highly elevated drug concentrations, vastly exceeding the MIC (Stevens et al. 2004). For example, one C. albicans strain undergoing paradoxical growth showed a $900 \%$ increase in chitin content (Clemons et al. 2006). The paradoxical effect is eliminated by chitin synthase inhibitor nikkomycin $\mathrm{Z}$ and calcineurin inhibitors (Shields et al. 2011).

\section{Hsp90}

Hsp90 orchestrates cellular stress-response circuitry that has a profound impact not only on azole resistance, but also on echinocandin resistance. Genetic or pharmacological compromise of Hsp90 function reduces basal echinocandin tolerance and resistance of C. albicans, C. glabrata, and A. fumigatus (Cowen and Lindquist 2005; Cowen 2009; Cowen et al. 2009; Singh et al. 2009; Singh-Babak et al. 2012; Lamoth et al. 2014a). Inhibition of Hsp90 reduces echinocandin resistance acquired by mutation in the drug target, and resistance that evolved in the human host (Singh et al. 2009; Singh-Babak et al. 2012). Hsp90 affects resistance to echinocandins through its client proteins calcineurin and Mkc1 (Singh et al. 2009; LaFayette et al. 2010). The Hsp90 cochaperone Sgt1 is also required for echinocandin tolerance and resistance acquired by mutation in the drug target (Shapiro et al. 2012). Hsp90 inhibitors in clinical development for cancer enhance the efficacy of echinocandins against $A$. fumigatus in the G. mellonella model of pathogenesis (Cowen et al. 2009), and genetic reduction of Hsp90 levels enhances the efficacy of echinocandins against $C$. albicans in murine models of systemic infection (Singh et al. 2009). Collectively, these studies suggest a broad therapeutic potential of targeting Hsp90 in enhancing the efficacy of the two leading classes of antifungal drugs against diverse fungal pathogens.

\section{Cell Integrity Circuit}

Cell wall integrity signaling is regulated by Hsp90 and is crucial for chitin synthesis, with profound effects on echinocandin tolerance and resistance. In S. cerevisiae, exposure to echinocandins induces genes from the PKC cell wall integrity-signaling pathway (Reinoso-Martin et al. 2003). Deletion of genes encoding cell wall integrity components, such as WSC1, PKC1, BCK1, and SLT2, confers hypersusceptibility to echinocandins (Reinoso-Martin et al. 2003; Markovich et al. 2004). Defects in cell wall integrity, such as those induced by the echinocandins, are sensed by transmembrane proteins of the Wsc family and Mid2, which then activate the GTPase Rhol. Rhol positively regulates multiple effectors including $\mathrm{Pkcl}$, as well as the echinocandin targets Fks1 and Fks2 (Shapiro et al. 2011). In C. albicans, the cell integrity circuitry is also implicated in mediating crucial responses to the cell wall stress induced by echinocandins. The terminal MAPK of the C. albicans $\mathrm{PKC}$ pathway, Mkc1, is induced by echinocandins and is required for basal tolerance (Wiederhold et al. 2005; LaFayette et al. 2010). Consistent with the importance of cell wall integrity signaling in echinocandin resistance, a potent and selective fungal Pkcl kinase inhibi- 
tor is synergistic with echinocandins against C. albicans (Sussman et al. 2004). The broadspectrum protein kinase inhibitor staurosporine is also synergistic with echinocandins against Candida and Aspergillus (Markovich et al. 2004; LaFayette et al. 2010). The cell wall integrity circuitry is not only crucial for responses to cell wall stress induced by echinocandins, but it is also required for cell membrane stress induced by azoles (LaFayette et al. 2010), highlighting its central role in mediating antifungal drug resistance.

\section{CONCLUDING REMARKS}

Antifungal therapy continues to be an important element of patient management for fungal diseases, and the development of both monoresistant and multidrug-resistant strains will be a challenge for the medical community. The mechanisms contributing to azole and echinocandin resistance are now well characterized and include reducing drug-target interactions either by modifying the target (drug affinity changes or target abundance) or by reducing the effective cellular content of drug (ABC or MFS drug pumps, biofilm glucan trap). $C$. albicans shows a full complement of resistance mechanisms, yet not all mechanisms are present in all fungal strains despite the genetic potential. Much progress has been made in understanding the importance of biofilms, as they convert normally susceptible planktonic cells into highly resistant cell communities. Similarly, a great deal has been learned about the genetic regulatory elements that influence overexpression of ERG11 and FKS genes, as well as ABC and MFS transporters. Fungal cells are dynamic and adapt readily to environmental challenges. Compensatory responses involving enhanced chitin biosynthesis following inhibition of glucan biosynthesis by echinocandin action helps maintain cell wall integrity. Critical cellular factors, such as Hsp90, stabilize enzymes during stress, thereby promoting cell survival. All components contribute to the development of cells, which transiently adapt to drug exposure with the potential to more fully breakthrough therapy by induction of more permanent resistance mechanisms. A detailed understanding of the principal resistance mechanisms and the factors that contribute to their evolution is important for developing new diagnostic approaches to more easily identify drug resistance and create new strategies for therapeutic intervention that can prevent and overcome resistance.

\section{REFERENCES}

Akache B, MacPherson S, Sylvain M-A, Turcotte B. 2004. Complex interplay among regulators of drug resistance genes in Saccharomyces cerevisiae. J Biol Chem 279: 27855-27860.

Akins RA. 2005. An update on antifungal targets and mechanisms of resistance in Candida albicans. Med Mycol 43 285-318.

Alarco AM, Raymond M. 1999. The bZip transcription factor Cap 1p is involved in multidrug resistance and oxidative stress response in Candida albicans. J Bacteriol 181: 700-708.

Antonovics J, Abbate JL, Baker CH, Daley D, Hood ME, Jenkins CE, Johnson LJ, Murray JJ, Panjeti V, Rudolf VH, et al. 2007. Evolution by any other name: Antibiotic resistance and avoidance of the E-word. PLoS Biol 5: e30.

Arendrup MC, Mavridou E, Mortensen KL, Snelders E, Frimodt-Moller N, Khan H, Melchers WJ, Verweij PE. 2010. Development of azole resistance in Aspergillus fumigatus during azole therapy associated with change in virulence. PLOS ONE 5: e10080.

Arendrup MC, Perlin DS, Jensen RH, Howard SJ, Goodwin J, Hope W. 2012. Differential in vivo activity of anidulafungin, caspofungin and micafungin against Candida glabrata with and without FKS resistance mutations. Antimicrob Agents Chemother 56: 2435-2442.

Bachmann SP, Ramage G, VandeWalle K, Patterson TF, Wickes BL, Lopez-Ribot JL. 2003. Antifungal combinations against Candida albicans biofilms in vitro. Antimicrob Agents Chemother 47: 3657-3659.

Barchiesi F, Calabrese D, Sanglard D, Falconi Di Francesco L, Caselli F, Giannini D, Giacometti A, Gavaudan S, Scalise G. 2000. Experimental induction of fluconazole resistance in Candida tropicalis ATCC 750. Antimicrob Agents Chemother 44: 1578-1584.

Ben-Ami R, Lewis RE, Kontoyiannis DP. 2008. Immunocompromised hosts: Immunopharmacology of modern antifungals. Clin Infect Dis 47: 226-235.

Ben-Ami R, Garcia-Effron G, Lewis RE, Gamarra S, Leventakos K, Perlin DS, Kontoyiannis DP. 2011. Fitness and virulence cost of Candida albicans FKS1 hot spot mutations associated with echinocandin resistance. J Infect Dis 204: 626-635.

Bonhomme J, d'Enfert C. 2013. Candida albicans biofilms: Building a heterogeneous, drug-tolerant environment. Curr Opin Microbiol 16: 398-403.

Borst A, Raimer MT, Warnock DW, Morrison CJ, Arthington-Skaggs BA. 2005. Rapid acquisition of stable azole resistance by Candida glabrata isolates obtained before 


\section{L.E. Cowen et al.}

the clinical introduction of fluconazole. Antimicrob Agents Chemother 49: 783-787.

Bouchara J, Zouhair R, Le Boudouil S, Renier G, Filmon R, Chabasse D, Hallet J, Defontaine A. 2000. In-vivo selection of an azole-resistant petite mutant of Candida glabrata. J Med Microbiol 49: 977-984.

Bowyer P, Denning DW. 2013. Environmental fungicides and triazole resistance in Aspergillus. Pest Manag Sci 70: $173-178$.

Braun BR, van het Hoog M, Denfert C, Martchenko M, Dungan J, Kuo A, Inglis DO, Uhl MA, Hogues H, Berriman M, et al. 2005. A human-curated annotation of the Candida albicans genome. PLoS Genet 1: 36-57.

Brown GD, Denning DW, Gow NA, Levitz SM, Netea MG, White TC. 2012. Hidden killers: Human fungal infections. Sci Transl Med 4: 165rv113.

Brun S, Aubry C, Lima O, Filmon R, Bergès T, Chabasse D, Bouchara J-P. 2003. Relationships between respiration and susceptibility to azole antifungals in Candida glabrata. Antimicrob Agents Chemother 47: 847-853.

Brun S, Berges T, Poupard P, Vauzelle-Moreau C, Renier G, Chabasse D, Bouchara J. 2004. Mechanisms of azole resistance in petite mutants of Candida glabrata. Antimicrob Agents Chemother 48: 1788-1796.

Calabrese D, Bille J, Sanglard D. 2000. A novel multidrug efflux transporter gene of the major facilitator superfamily from Candida albicans (FLU1) conferring resistance to fluconazole. Microbiology 146: 2743-2754.

Camps SM, Dutilh BE, Arendrup MC, Rijs AJ, Snelders E, Huynen MA, Verweij PE, Melchers WJ. 2012a. Discovery of a hapE mutation that causes azole resistance in Aspergillus fumigatus through whole genome sequencing and sexual crossing. PLoS ONE 7: e50034.

Camps SM, Rijs AJ, Klaassen CH, Meis JF, O'Gorman CM, Dyer PS, Melchers WJ, Verweij PE. 2012b. Molecular epidemiology of Aspergillus fumigatus isolates harboring the $\mathrm{TR}_{34} / \mathrm{L} 98 \mathrm{H}$ azole resistance mechanism. J Clin Microbiol 50: 2674-2680.

Camps SM, van der Linden JW, Li Y, Kuijper EJ, van Dissel JT, Verweij PE, Melchers WJ. 2012c. Rapid induction of multiple resistance mechanisms in Aspergillus fumigatus during azole therapy: A case study and review of the literature. Antimicrob Agents Chemother 56: 10-16.

Casalinuovo IA, Di Francesco P, Garaci E. 2004. Fluconazole resistance in Candida albicans: A review of mechanisms. Eur Rev Med Pharmacol Sci 8: 69-77.

Caudle KE, Barker KS, Wiederhold NP, Xu L, Homayouni R, Rogers PD. 2011. Genomewide expression profile analysis of the Candida glabrata Pdr1 regulon. Eukaryot Cell 10: $373-383$.

Chandra J, Zhou G, Ghannoum MA. 2005. Fungal biofilms and antimycotics. Curr Drug Targets 6: 887-894.

Chen C-G, Yang Y-L, Shih H-I, Su C-L, Lo H-J. 2004. CaNdt80 is involved in drug resistance in Candida albicans by regulating CDR1. Antimicrob Agents Chemother 48: 4505-4512.

Chen J, Li H, Li R, Bu D, Wan Z. 2005. Mutations in the cyp51A gene and susceptibility to itraconazole in Aspergillus fumigatus serially isolated from a patient with lung aspergilloma. J Antimicrob Chemother 55: 31-37.
Chen C, Yang Y, Tseng K, Shih H, Liou C, Lin C, Lo H. 2009. Replp negatively regulating $M D R 1$ efflux pump involved in drug resistance in Candida albicans. Fungal Genet Biol 46: 714-710.

Chowdhary A, Kathuria S, Xu J, Sharma C, Sundar G, Singh PK, Gaur SN, Hagen F, Klaassen CH, Meis JF. 2012. Clonal expansion and emergence of environmental multipletriazole-resistant Aspergillus fumigatus strains carrying the $\mathrm{TR}_{34} / \mathrm{L} 98 \mathrm{H}$ mutations in the cyp51A gene in India. PLOS ONE 7: e52871.

Clemons KV, Espiritu M, Parmar R, Stevens DA. 2006. Assessment of the paradoxical effect of caspofungin in therapy of candidiasis. Antimicrob Agents Chemother 50: 1293-1297.

Coleman JJ, Mylonakis E. 2009. Efflux in fungi: La pièce de résistance. PLoS Pathog 5: e1000486.

Coste AT, Karababa M, Ischer F, Bille J, Sanglard D. 2004. $T A C 1$, transcriptional activator of $C D R$ genes, is a new transcription factor involved in the regulation of Candida albicans $\mathrm{ABC}$ transporters $\mathrm{CDR} 1$ and $\mathrm{CDR} 2$. Eukaryot Cell 3: 1639-1652.

Coste A, Turner V, Ischer F, Morschhäuser J, Forche A, Selmecki A, Berman J, Bille J, Sanglard D. 2006. A mutation in Tac1p, a transcription factor regulating CDR1 and $C D R 2$, is coupled with loss of heterozygosity at chromosome 5 to mediate antifungal resistance in Candida albicans. Genetics 172: 2139-2156.

Coste A, Selmecki A, Forche A, Diogo D, Bougnoux M-E, D'enfert C, Berman J, Sanglard D. 2007. Genotypic evolution of azole resistance mechanisms in sequential Candida albicans isolates. Eukaryot Cell 6: 1889-1904.

Coste AT, Crittin J, Bauser C, Rohde B, Sanglard D. 2009. Functional analysis of cis- and trans-acting elements of the Candida albicans CDR2 promoter with a novel promoter reporter system. Eukaryot Cell 8: 1250-1267.

Cota JM, Grabinski JL, Talbert RL, Burgess DS, Rogers PD, Edlind TD, Wiederhold NP. 2008. Increases in SLT2 expression and chitin content are associated with incomplete killing of Candida glabrata by caspofungin. Antimicrob Agents Chemother 52: 1144-1146.

Cowen LE. 2008. The evolution of fungal drug resistance: Modulating the trajectory from genotype to phenotype. Nat Rev Microbiol 6: 187-198.

Cowen LE. 2009. Hsp90 orchestrates stress response signaling governing fungal drug resistance. PLoS Pathog 5: e1000471.

Cowen LE. 2013. The fungal Achilles' heel: Targeting Hsp90 to cripple fungal pathogens. Curr Opin Microbiol 16: 377-384.

Cowen LE, Lindquist S. 2005. Hsp90 potentiates the rapid evolution of new traits: Drug resistance in diverse fungi. Science 309: 2185-2189.

Cowen LE, Steinbach WJ. 2008. Stress, drugs, and evolution: The role of cellular signaling in fungal drug resistance. Eukaryot Cell 7: 747-764.

Cowen LE, Carpenter AE, Matangkasombut O, Fink GR, Lindquist S. 2006. Genetic architecture of Hsp90-dependent drug resistance. Eukaryot Cell 5: 2184-2188.

Cowen LE, Singh SD, Kohler JR, Collins C, Zaas AK, Schell WA, Aziz H, Mylonakis E, Perfect JR, Whitesell L, et al. 2009. Harnessing Hsp90 function as a powerful, broadly 
Drug Resistance Mechanisms

effective therapeutic strategy for fungal infectious disease. Proc Natl Acad Sci 106: 2818-2823.

Cruz MC, Goldstein AL, Blankenship JR, Del Poeta M, Davis D, Cardenas ME, Perfect JR, McCusker JH, Heitman J. 2002. Calcineurin is essential for survival during membrane stress in Candida albicans. EMBO J 21: 546-559.

da Silva Ferreira ME, Malavazi I, Savoldi M, Brakhage AA, Goldman MH, Kim HS, Nierman WC, Goldman GH. 2006. Transcriptome analysis of Aspergillus fumigatus exposed to voriconazole. Curr Genet 50: 32-44.

de Micheli M, Bille J, Schueller C, Sanglard D. 2002. A common drug-responsive element mediates the upregulation of the Candida albicans $\mathrm{ABC}$ transporters $C D R 1$ and $C D R 2$, two genes involved in antifungal drug resistance. Mol Microbiol 43: 1197-1214.

d'Enfert C. 2006. Biofilms and their role in the resistance of pathogenic Candida to antifungal agents. Curr Drug Targets 7: 465-470.

Denning DW, Venkateswarlu K, Oakley KL, Anderson MJ, Manning NJ, Stevens DA, Warnock DW, Kelly SL. 1997. Itraconazole resistance in Aspergillus fumigatus. Antimicrob Agents Chemother 41: 1364-1368.

Desai JV, Bruno VM, Ganguly S, Stamper RJ, Mitchell KF, Solis N, Hill EM, Xu W, Filler SG, Andes DR, et al. 2013. Regulatory role of glycerol in Candida albicans biofilm formation. MBio 4: e00637-e00612.

Dunkel N, Blass J, Rogers P, Morschhauser J. 2008. Mutations in the multidrug resistance regulator MRR1, followed by loss of heterozygosity, are the main cause of MDR1 overexpression in fluconazole-resistant Candida albicans strains. Mol Microbiol 69: 827-840.

Eddouzi J, Parker JE, Vale-Silva LA, Coste A, Ischer F, Kelly S, Manai M, Sanglard D. 2013. Molecular mechanisms of drug resistance in clinical Candida species isolated from Tunisian hospitals. Antimicrob Agents Chemother 57: 3182-3193.

Eng WK, Faucette L, McLaughlin MM, Cafferkey R, Koltin Y, Morris RA, Young PR, Johnson RK, Livi GP. 1994. The yeast FKS1 gene encodes a novel membrane protein, mutations in which confer FK506 and cyclosporin A hypersensitivity and calcineurin-dependent growth. Gene 151: 61-71.

Fanning S, Mitchell AP. 2012. Fungal biofilms. PLoS Pathog 8: e1002585.

Ferrari S, Ischer F, Calabrese D, Posteraro B, Sanguinetti M, Fadda G, Rohde B, Bauser C, Bader O, Sanglard D. 2009. Gain of function mutations in CgPDR1 of Candida glabrata not only mediate antifungal resistance but also enhance virulence. PLoS Pathog 5: e1000268.

Ferrari S, Sanguinetti M, De Bernardis F, Torelli R, Posteraro B, Vandeputte P, Sanglard D. 2011a. Loss of mitochondrial functions associated with azole resistance in Candida glabrata also results in enhanced virulence in mice. Antimicrob Agents Chemother 55: 1852-1860.

Ferrari S, Sanguinetti M, Torelli R, Posteraro B, Sanglard D. 2011b. Contribution of CgPDR1-regulated genes in enhanced virulence of azole-resistant Candida glabrata. PLOS ONE 6: e17589.

Fiori A, Van Dijck P. 2012. Potent synergistic effect of doxycycline with fluconazole against Candida albicans is mediated by interference with iron homeostasis. Antimicrob Agents Chemother 56: 3785-3796.
Flowers SA, Barker KS, Berkow EL, Toner G, Chadwick SG, Gygax SE, Morschhauser J, Rogers PD. 2012. Gain-offunction mutations in UPC2 are a frequent cause of ERG11 upregulation in azole-resistant clinical isolates of Candida albicans. Eukaryot Cell 11: 1289-1299.

Fraczek MG, Bromley M, Bowyer P. 2011. An improved model of the Aspergillus fumigatus CYP51A protein. Antimicrob Agents Chemother 55: 2483-2486.

Fraczek MG, Bromley M, Buied A, Moore CB, Rajendran R, Rautemaa R, Ramage G, Denning DW, Bowyer P. 2013. The $c d r 1 B$ efflux transporter is associated with noncyp51a-mediated itraconazole resistance in Aspergillus fumigatus. J Antimicrob Chemother 68: 1486-1496.

Franz R, Kelly SL, Lamb DC, Kelly DE, Ruhnke M, Morschhauser J. 1998. Multiple molecular mechanisms contribute to a stepwise development of fluconazole resistance in clinical Candida albicans strains. Antimicrob Agents Chemother 42: 3065-3072.

Garcia-Effron G, Katiyar SK, Park S, Edlind TD, Perlin DS. 2008. A naturally occurring proline-to-alanine amino acid change in Fks1p in Candida parapsilosis, Candida orthopsilosis, and Candida metapsilosis accounts for reduced echinocandin susceptibility. Antimicrob Agents Chemother 52: 2305-2312.

Garcia-Effron G, Lee S, Park S, Cleary JD, Perlin DS. 2009a. Effect of Candida glabrata FKS1 and FKS2 mutations on echinocandin sensitivity and kinetics of $1,3-\beta$-D-glucan synthase: Implication for the existing susceptibility breakpoint. Antimicrob Agents Chemother 53: 36903699.

Garcia-Effron G, Park S, Perlin DS. 2009b. Correlating echinocandin MIC and kinetic inhibition of $f k s 1$ mutant glucan synthases for Candida albicans: Implications for interpretive breakpoints. Antimicrob Agents Chemother 53: $112-122$.

Gaur M, Puri N, Manoharlal R, Rai V, Mukhopadhayay G, Choudhury D, Prasad R. 2008. MFS transportome of the human pathogenic yeast Candida albicans. BMC Genomics 9: 579.

Goldman G, da Silva Ferreira M, dos Reis Marques E, Savoldi M, Perlin D, Park S, Godoy Martinez P, Goldman M, Colombo A. 2004. Evaluation of fluconazole resistance mechanisms in Candida albicans clinical isolates from HIV-infected patients in Brazil. Diagn Microbiol Infect Dis 50: 25-32.

Groll AH, Piscitelli SC, Walsh TJ. 1998. Clinical pharmacology of systemic antifungal agents: A comprehensive review of agents in clinical use, current investigational compounds, and putative targets for antifungal drug development. Adv Pharmacol 44: 343-500.

Gulshan K, Moye-Rowley WS. 2007. Multidrug resistance in fungi. Eukaryot Cell 6: 1933-1942.

Harrison BD, Hashemi J, Bibi M, Pulver R, Bavli D, Nahmias Y, Wellington M, Sapiro G, Berman J. 2014. A tetraploid intermediate precedes aneuploid formation in yeasts exposed to fluconazole. PLoS Biol 12: e1001815.

Healey KR, Katiyar SK, Castanheira M, Pfaller MA, Edlind TD. 2011. Candida glabrata mutants demonstrating paradoxical reduced caspofungin susceptibility but increased micafungin susceptibility. Antimicrob Agents Chemother 55: 3947-3949. 


\section{L.E. Cowen et al.}

Healey KR, Katiyar SK, Raj S, Edlind TD. 2012. CRS-MIS in Candida glabrata: Sphingolipids modulate echinocandin-Fks interaction. Mol Microbiol 86: 303-313.

Hiller D, Sanglard D, Morschhäuser J. 2006. Overexpression of the MDR1 gene is sufficient to confer increased resistance to toxic compounds in Candida albicans. Antimicrob Agents Chemother 50: 1365-1371.

Hope WW, Tabernero L, Denning DW, Anderson MJ. 2004 Molecular mechanisms of primary resistance to flucytosine in Candida albicans. Antimicrob Agents Chemother 48: $4377-4386$.

Howard SJ, Arendrup MC. 2011. Acquired antifungal drug resistance in Aspergillus fumigatus: Epidemiology and detection. Med Mycol 49: S90-S95.

Howard SJ, Cerar D, Anderson MJ, Albarrag A, Fisher MC, Pasqualotto AC, Laverdiere M, Arendrup MC, Perlin DS Denning DW. 2009. Frequency and evolution of azole resistance in Aspergillus fumigatus associated with treatment failure. Emerg Infect Dis 15: 1068-1076.

Howard SJ, Lestner JM, Sharp A, Gregson L, Goodwin J, Slater J, Majithiya JB, Warn PA, Hope WW. 2011. Pharmacokinetics and pharmacodynamics of posaconazole for invasive pulmonary aspergillosis: Clinical implications for antifungal therapy. J Infect Dis 203: 1324-1332.

Jiang C, Dong D, Yu B, Cai G, Wang X, Ji Y, Peng Y. 2013. Mechanisms of azole resistance in 52 clinical isolates of Candida tropicalis in China. J Antimicrob Chemother 68: $778-785$.

Jimenez-Ortigosa C, Aimanianda V, Muszkieta L, Mouyna I, Alsteens D, Pire S, Beau R, Krappmann S, Beauvais A, Dufrene YF, et al. 2012. Chitin synthases with a myosin motor-like domain control the resistance of Aspergillus fumigatus to echinocandins. Antimicrob Agents Chemother 56: 6121-6131.

Johnson ME, Edlind TD. 2012. Topological and mutational analysis of Saccharomyces cerevisiae Fks1. Eukaryot Cell 11: $952-960$.

Johnson ME, Katiyar SK, Edlind TD. 2011. New Fks hot spot for acquired echinocandin resistance in Saccharomyces cerevisiae and its contribution to intrinsic resistance of Scedosporium species. Antimicrob Agents Chemother 55: 3774-3781.

Kartsonis N, Killar J, Mixson L, Hoe CM, Sable C, Bartizal K, Motyl M. 2005. Caspofungin susceptibility testing of isolates from patients with esophageal candidiasis or invasive candidiasis: Relationship of MIC to treatment outcome. Antimicrob Agents Chemother 49: 3616-3623.

Kathiravan MK, Salake AB, Chothe AS, Dudhe PB, Watode RP, Mukta MS, Gadhwe S. 2012. The biology and chemistry of antifungal agents: A review. Bioorg Med Chem 20: 5678-5698.

Katiyar SK, Edlind TD. 2009. Role for Fks1 in the intrinsic echinocandin resistance of Fusarium solani as evidenced by hybrid expression in Saccharomyces cerevisiae. Antimicrob Agents Chemother 53: 1772-1778.

Katiyar S, Pfaller M, Edlind T. 2006. Candida albicans and Candida glabrata clinical isolates exhibiting reduced echinocandin susceptibility. Antimicrob Agents Chemother 50: 2892-2894.

Katiyar SK, Alastruey-Izquierdo A, Healey KR, Johnson ME, Perlin DS, Edlind TD. 2012. Fks1 and Fks2 are functionally redundant but differentially regulated in Candida glabrata: Implications for echinocandin resistance. Antimicrob Agents Chemother 56: 6304-6309.

Kumamoto CA. 2002. Candida biofilms. Curr Opin Microbiol 5: 608-611.

LaFayette SL, Collins C, Zaas AK, Schell WA, BetancourtQuiroz M, Gunatilaka AA, Perfect JR, Cowen LE. 2010. PKC signaling regulates drug resistance of the fungal pathogen Candida albicans via circuitry comprised of Mkc1, calcineurin, and Hsp90. PLoS Pathog 6: e1001069.

Lamoth F, Juvvadi PR, Gehrke C, Asfaw YG, Steinbach WJ. 2014a. Transcriptional activation of heat shock protein 90 mediated via a proximal promoter region as trigger of caspofungin resistance in Aspergillus fumigatus. J Infect Dis 209: 473-481.

Lamoth F, Juvvadi PR, Soderblom EJ, Moseley MA, Asfaw YG, Steinbach WJ. 2014b. Identification of a key lysine residue in heat shock protein 90 required for azole and echinocandin resistance in Aspergillus fumigatus. Antimicrob Agents Chemother 58: 1889-1896.

Lamping E, Monk BC, Niimi K, Holmes AR, Tsao S, Tanabe K, Niimi M, Uehara Y, Cannon RD. 2007. Characterization of three classes of membrane proteins involved in fungal azole resistance by functional hyperexpression in Saccharomyces cerevisiae. Eukaryot Cell 6: 1150-1165.

Lamping E, Baret PV, Holmes AR, Monk BC, Goffeau A, Cannon RD. 2010. Fungal PDR transporters: Phylogeny, topology, motifs and function. Fungal Genet Biol 47: 127-142.

Lavoie H, Sellam A, Askew C, Nantel A, Whiteway M. 2008. A toolbox for epitope-tagging and genome-wide location analysis in Candida albicans. BMC Genomics 9: 578

Lee KK, MacCallum DM, Jacobsen MD, Walker LA, Odds FC, Gow NA, Munro CA. 2012. Elevated cell wall chitin in Candida albicans confers echinocandin resistance in vivo. Antimicrob Agents Chemother 56: 208-217.

Liu TT, Znaidi S, Barker KS, Xu L, Homayouni R, Saidane S, Morschhäuser J, Nantel A, Raymond M, Rogers PD. 2007. Genome-wide expression and location analyses of the Candida albicans Taclp regulon. Eukaryot Cell 6: $2122-2138$

Lopez-Ribot JL, McAtee RK, Perea S, Kirkpatrick WR, Rinaldi MG, Patterson TF. 1999. Multiple resistant phenotypes of Candida albicans coexist during episodes of oropharyngeal candidiasis in human immunodeficiency virus-infected patients. Antimicrob Agents Chemother 43: $1621-1630$

Lupetti A, Danesi R, Campa M, Del Tacca M, Kelly S. 2002. Molecular basis of resistance to azole antifungals. Trends Mol Med 8: 76-81.

MacCallum DM, Coste A, Ischer F, Jacobsen MD, Odds FC, Sanglard D. 2010. Genetic dissection of azole resistance mechanisms in Candida albicans and their validation in a mouse model of disseminated infection. Antimicrob Agents Chemother 54: 1476-1483.

MacPherson S, Akache B, Weber S, De Deken X, Raymond M, Turcotte B. 2005. Candida albicans zinc cluster protein $\mathrm{Upc} 2 \mathrm{p}$ confers resistance to antifungal drugs and is an activator of ergosterol biosynthetic genes. Antimicrob Agents Chemother 49: 1745-1752.

Mamnun YM, Pandjaitan R, Mahé Y, Delahodde A, Kuchler K. 2002. The yeast zinc finger regulators Pdrlp and Pdr3p 
control pleiotropic drug resistance (PDR) as homo- and heterodimers in vivo. Mol Microbiol 46: 1429-1440.

Manavathu EK, Vazquez JA, Chandrasekar PH. 1999. Reduced susceptibility in laboratory-selected mutants of Aspergillus fumigatus to itraconazole due to decreased intracellular accumulation of the antifungal agent. Int $J$ Antimicrob Agents 12: 213-219.

Manoharlal R, Gaur NA, Panwar SL, Morschhauser J, Prasad R. 2008. Transcriptional activation and increased mRNA stability contribute to overexpression of CDR1 in azoleresistant Candida albicans. Antimicrob Agents Chemother 52: $1481-1492$.

Manoharlal R, Gorantala J, Sharma M, Sanglard D, Prasad R. 2010. PAP1 [ poly(A) polymerase 1] homozygosity and hyperadenylation are major determinants of increased mRNA stability of CDR1 in azole-resistant clinical isolates of Candida albicans. Microbiology 156: 313-326.

Mansfield B, Oltean H, Oliver B, Hoot S, Leyde S, Hedstrom L, White T. 2010. Azole drugs are imported by facilitated diffusion in Candida albicans and other pathogenic fungi. PLoS Pathog 6.

Marichal P, Vanden Bossche H, Odds F, Nobels G, Warnock D, Timmerman V, Van Broeckhoven C, Fay S, MoseLarsen P. 1997. Molecular biological characterization of an azole-resistant Candida glabrata isolate. Antimicrob Agents Chemother 41: 2229-2237.

Markovich S, Yekutiel A, Shalit I, Shadkchan Y, Osherov N. 2004. Genomic approach to identification of mutations affecting caspofungin susceptibility in Saccharomyces cerevisiae. Antimicrob Agents Chemother 48: 3871-3876.

Marr K, Lyons C, Ha K, Rustad T, White T. 2001. Inducible azole resistance associated with a heterogeneous phenotype in Candida albicans. Antimicrob Agents Chemother 45: 52-59.

Martinez M, Lopez-Ribot J, Kirkpatrick W, Bachmann S, Perea S, Ruesga M, Patterson T. 2002. Heterogeneous mechanisms of azole resistance in Candida albicans clinical isolates from an HIV-infected patient on continuous fluconazole therapy for oropharyngeal candidosis. J Antimicrob Chemother 49: 515-524.

Mayer FL, Wilson D, Jacobsen ID, Miramon P, Slesiona S, Bohovych IM, Brown AJ, Hube B. 2012. Small but crucial: The novel small heat shock protein Hsp21 mediates stress adaptation and virulence in Candida albicans. PLoS ONE 7: e38584.

Mellado E, Garcia-Effron G, Alcazar-Fuoli L, Melchers WJ, Verweij PE, Cuenca-Estrella M, Rodriguez-Tudela JL. 2007. A new Aspergillus fumigatus resistance mechanism conferring in vitro cross-resistance to azole antifungals involves a combination of cyp51A alterations. Antimicrob Agents Chemother 51: 1897-1904.

Mogavero S, Tavanti A, Senesi S, Rogers PD, Morschhauser J. 2011. Differential requirement of the transcription factor $\mathrm{Mcm} 1$ for activation of the Candida albicans multidrug efflux pump MDR1 by its regulators Mrr1 and Cap1. Antimicrob Agents Chemother 55: 2061-2066.

Monk BC, Goffeau A. 2008. Outwitting multidrug resistance to antifungals. Science 321: 367-369.

Morio F, Loge C, Besse B, Hennequin C, Le Pape P. 2010. Screening for amino acid substitutions in the Candida albicans Erg11 protein of azole-susceptible and azole-re- sistant clinical isolates: New substitutions and a review of the literature. Diagn Microbiol Infect Dis 66: 373-384.

Morschhauser J, Barker K, Liu T, Bla B, Homayouni R, Rogers P. 2007. The transcription factor Mrrlp controls expression of the MDR1 efflux pump and mediates multidrug resistance in Candida albicans. PLoS Pathog 3: e164.

Mortensen KL, Mellado E, Lass-Florl C, Rodriguez-Tudela JL, Johansen HK, Arendrup MC. 2010. Environmental study of azole-resistant Aspergillus fumigatus and other aspergilli in Austria, Denmark, and Spain. Antimicrob Agents Chemother 54: 4545-4549.

Mukherjee PK, Chandra J, Kuhn DM, Ghannoum MA. 2003. Mechanism of fluconazole resistance in Candida albicans biofilms: Phase-specific role of efflux pumps and membrane sterols. Infect Immun 71: 4333-4340.

Munro CA, Selvaggini S, de Bruijn I, Walker L, Lenardon MD, Gerssen B, Milne S, Brown AJ, Gow NA. 2007. The PKC, HOG and $\mathrm{Ca}^{2+}$ signalling pathways co-ordinately regulate chitin synthesis in Candida albicans. Mol Microbiol 63: 1399-1413.

Naar AM, Thakur JK. 2009. Nuclear receptor-like transcription factors in fungi. Genes Dev 23: 419-432.

Nascimento AM, Goldman GH, Park S, Marras SA, Delmas G, Oza U, Lolans K, Dudley MN, Mann PA, Perlin DS. 2003. Multiple resistance mechanisms among Aspergillus fumigatus mutants with high-level resistance to itraconazole. Antimicrob Agents Chemother 47: 1719-1726.

Nett JE, Crawford K, Marchillo K, Andes DR. 2010a. Role of Fks1p and matrix glucan in Candida albicans biofilm resistance to an echinocandin, pyrimidine, and polyene. Antimicrob Agents Chemother 54: 3505-3508.

Nett JE, Sanchez H, Cain MT, Andes DR. 2010b. Genetic basis of Candida biofilm resistance due to drug-sequestering matrix glucan. J Infect Dis 202: 171-175.

Nett JE, Sanchez H, Cain MT, Ross KM, Andes DR. 2011 Interface of Candida albicans biofilm matrix-associated drug resistance and cell wall integrity regulation. Eukaryot Cell 10: 1660-1669.

Niimi K, Maki K, Ikeda F, Holmes AR, Lamping E, Niimi M, Monk BC, Cannon RD. 2006. Overexpression of Candida albicans $C D R 1, C D R 2$, or MDR1 does not produce significant changes in echinocandin susceptibility. Antimicrob Agents Chemother 50: 1148-1155.

Nobile CJ, Nett JE, Hernday AD, Homann OR, Deneault JS, Nantel A, Andes DR, Johnson AD, Mitchell AP. 2009. Biofilm matrix regulation by Candida albicans Zap1. PLoS Biol 7: e1000133.

Noble JA, Tsai H-F, Suffis SD, Su Q, Myers TG, Bennett JE. 2013. STB5 is a negative regulator of azole resistance in Candida glabrata. Antimicrob Agents Chemother 57: 959967.

Odds FC, Brown AJ, Gow NA. 2003. Antifungal agents: Mechanisms of action. Trends Microbiol 11: 272-279.

Park S, Perlin D. 2005. Establishing surrogate markers for fluconazole resistance in Candida albicans. Microb Drug Resist 11: 232-238.

Park S, Kelly R, Kahn JN, Robles J, Hsu MJ, Register E, Li W, Vyas V, Fan H, Abruzzo G, et al. 2005. Specific substitutions in the echinocandin target Fkslp account for reduced susceptibility of rare laboratory and clinical Can- 


\section{L.E. Cowen et al.}

dida sp. isolates. Antimicrob Agents Chemother 49: 32643273.

Paul S, Schmidt JA, Moye-Rowley WS. 2011. Regulation of the CgPdrl transcription factor from the pathogen Candida glabrata. Eukaryot Cell 10: 187-197.

Perea S, Lopez-Ribot J, Kirkpatrick W, McAtee R, Santillan R, Martinez M, Calabrese D, Sanglard D, Patterson T. 2001. Prevalence of molecular mechanisms of resistance to azole antifungal agents in Candida albicans strains displaying high-level fluconazole resistance isolated from human immunodeficiency virus-infected patients. Antimicrob Agents Chemother 45: 2676-2684.

Perlin DS. 2007. Resistance to echinocandin-class antifungal drugs. Drug Resist Updat 10: 121-130.

Perlin DS. 2011a. Current perspectives on echinocandin class drugs. Future Microbiol 6: 441-457.

Perlin DS. 2011b. Echinocandin-resistant Candida: Molecular methods and phenotypes. Curr Fungal Infect Rep 5: 113-119.

Pfaller MA, Boyken L, Hollis RJ, Kroeger J, Messer SA, Tendolkar S, Diekema DJ. 2008a. In vitro susceptibility of invasive isolates of Candida spp. to anidulafungin, caspofungin, and micafungin: Six years of global surveillance. J Clin Microbiol 46: 150-156.

Pfaller MA, Diekema DJ, Ostrosky-Zeichner L, Rex JH, Alexander BD, Andes D, Brown SD, Chaturvedi V, Ghannoum MA, Knapp CC, et al. 2008b. Correlation of MIC with outcome for Candida species tested against caspofungin, anidulafungin, and micafungin: Analysis and proposal for interpretive MIC breakpoints. J Clin Microbiol 46: $2620-2629$.

Pfaller MA, Boyken L, Hollis RJ, Kroeger J, Messer SA, Tendolkar S, Jones RN, Turnidge J, Diekema DJ. 2010. Wildtype MIC distributions and epidemiological cutoff values for the echinocandins and Candida spp. J Clin Microbiol 48: $52-56$

Poláková S, Blume C, Zárate JA, Mentel M, Jørck-Ramberg D, Stenderup J, Piskur J. 2009. Formation of new chromosomes as a virulence mechanism in yeast Candida glabrata. Proc Natl Acad Sci 106: 2688-2693.

Prasad R, Goffeau A. 2012. Yeast ATP-binding cassette transporters conferring multidrug resistance. Аnпu Rev Microbiol 66: 39-63.

Ramage G, Bachmann S, Patterson TF, Wickes BL, LopezRibot JL. 2002. Investigation of multidrug efflux pumps in relation to fluconazole resistance in Candida albicans biofilms. J Antimicrob Chemother 49: 973-980.

Ramage G, Mowat E, Jones B, Williams C, Lopez-Ribot J. 2009. Our current understanding of fungal biofilms. Crit Rev Microbiol 35: 340-355.

Redding SW, Kirkpatrick WR, Coco BJ, Sadkowski L, Fothergill AW, Rinaldi MG, Eng TY, Patterson TF. 2002. Candida glabrata oropharyngeal candidiasis in patients receiving radiation treatment for head and neck cancer. $J$ Clin Microbiol 40: 1879-1881.

Reinoso-Martin C, Schuller C, Schuetzer-Muehlbauer M, Kuchler K. 2003. The yeast protein kinase C cell integrity pathway mediates tolerance to the antifungal drug caspofungin through activation of Slt2p mitogen-activated protein kinase signaling. Eukaryot cell 2: 1200-1210.
Riggle P, Kumamoto C. 2006. Transcriptional regulation of $M D R 1$, encoding a drug efflux determinant, in fluconazole-resistant Candida albicans strains through an Mcmlp binding site. Eukaryot Cell 5: 1957-1968.

Robbins N, Uppuluri P, Nett J, Rajendran R, Ramage G, Lopez-Ribot JL, Andes D, Cowen LE. 2011. Hsp90 governs dispersion and drug resistance of fungal biofilms. PLoS Pathog 7: e1002257.

Robbins N, Leach MD, Cowen LE. 2012. Lysine deacetylases Hda1 and Rpd3 regulate Hsp90 function thereby governing fungal drug resistance. Cell Rep 2: 878-888.

Rodero L, Mellado E, Rodriguez AC, Salve A, Guelfand L, Cahn P, Cuenca-Estrella M, Davel G, Rodriguez-Tudela JL. 2003. G484S amino acid substitution in lanosterol 14$\alpha$ demethylase (ERG11) is related to fluconazole resistance in a recurrent Cryptococcus neoformans clinical isolate. Antimicrob Agents Chemother 47: 3653-3656.

Rogers PD, Vermitsky JP, Edlind TD, Hilliard GM. 2006. Proteomic analysis of experimentally induced azole resistance in Candida glabrata. J Antimicrob Chemother 58: 434-438.

Rognon B, Kozovska Z, Coste AT, Pardini G, Sanglard D. 2006. Identification of promoter elements responsible for the regulation of MDR1 from Candida albicans, a major facilitator transporter involved in azole resistance. Microbiology 152: 3701-3722.

Sanglard D. 2011. Diagnosis of antifungal drug resistance mechanisms in fungal pathogens: Transcriptional gene regulation. Curr Fungal Infect Rep 5: 157-167.

Sanglard D, Kuchler K, Ischer F, Pagani JL, Monod M, Bille J. 1995. Mechanisms of resistance to azole antifungal agents in Candida albicans isolates from AIDS patients involve specific multidrug transporters. Antimicrob Agents Chemother 39: 2378-2386.

Sanglard D, Ischer F, Monod M, Bille J. 1996. Susceptibilities of Candida albicans multidrug transporter mutants to various antifungal agents and other metabolic inhibitors. Antimicrob Agents Chemother 40: 2300-2305.

Sanglard D, Ischer F, Koymans L, Bille J. 1998a. Amino acid substitutions in the cytochrome P450 lanosterol 14 $\alpha$-demethylase (CYP51A1) from azole-resistant Candida albicans clinical isolates contributing to the resistance to azole antifungal agents. Antimicrob Agents Chemother 42: $241-253$.

Sanglard D, Isher I, Calabrese D, de Micheli M, Bille J. 1998b. Multiple mechanisms to azole antifungals in yeast. Drug Resist Updat 1: 255-265.

Sanglard D, Ischer F, Calabrese D, Majcherczyk PA, Bille J. 1999. The ATP binding cassette transporter gene CgCDR1 from Candida glabrata is involved in the resistance of clinical isolates to azole antifungal agents. Antimicrob Agents Chemother 43: 2753-2765.

Sanglard D, Ischer F, Bille J. 2001. Role of ATP-bindingcassette transporter genes in high-frequency acquisition of resistance to azole antifungals in Candida glabrata. Antimicrob Agents Chemother 45: 1174-1183.

Sanglard D, Ischer F, Marchetti O, Entenza J, Bille J. 2003. Calcineurin A of Candida albicans: Involvement in antifungal tolerance, cell morphogenesis and virulence. $\mathrm{Mol}$ Microbiol 48: 959-976.

Sanglard D, Coste A, Ferrari S. 2009. Antifungal drug resistance mechanisms in fungal pathogens from the perspec- 
tive of transcriptional gene regulation. FEMS Yeast Res 9: 1029-1050.

Sanguinetti M, Posteraro B, Fiori B, Ranno S, Torelli R, Fadda G. 2005. Mechanisms of azole resistance in clinical isolates of Candida glabrata collected during a hospital survey of antifungal resistance. Antimicrob Agents Chemother 49: 668-679.

Schillig R, Morschhauser J. 2013. Analysis of a fungus-specific transcription factor family, the Candida albicans zinc cluster proteins, by artificial activation. Mol Microbiol 89: 1003-1017.

Schubert S, Barker KS, Znaidi S, Schneider S, Dierolf F, Dunkel N, Aid M, Boucher G, Rogers PD, Raymond M, et al. 2011. Regulation of efflux pump expression and drug resistance by the transcription factors Mrr1, Upc2, and Cap1 in Candida albicans. Antimicrob Agents Chemother 55: 2212-2223.

Sellam A, Askew C, Epp E, Lavoie H, Whiteway M, Nantel A. 2009a. Genome-wide mapping of the coactivator Ada2p yields insight into the functional roles of SAGA/ADA complex in Candida albicans. Mol Biol Cell 20: 23892400.

Sellam A, Tebbji F, Nantel A. 2009b. Role of Ndt80p in sterol metabolism regulation and azole resistance in Candida albicans. Eukaryot Cell 8: 1174-1183.

Selmecki A, Forche A, Berman J. 2006. Aneuploidy and isochromosome formation in drug-resistant Candida albicans. Science 313: 367-370.

Selmecki AM, Dulmage K, Cowen LE, Anderson JB, Berman J. 2009. Acquisition of aneuploidy provides increased fitness during the evolution of antifungal drug resistance. PLoS Genet 5: e1000705.

Selmecki A, Forche A, Berman J. 2010. Genomic plasticity of the human fungal pathogen Candida albicans. Eukaryot Cell 9: 991-1008.

Shapiro RS, Robbins N, Cowen LE. 2011. Regulatory circuitry governing fungal development, drug resistance, and disease. Microbiol Mol Biol Rev 75: 213-267.

Shapiro RS, Zaas AK, Betancourt-Quiroz M, Perfect JR, Cowen LE. 2012. The Hsp90 co-chaperone Sgtl governs Candida albicans morphogenesis and drug resistance. PLoS ONE 7: e44734.

Shen H, An M-M, Wang DJ, Xu Z, Zhang J-D, Gao P-H, Cao Y-Y, Cao Y-B, Jiang Y-Y. 2007. Fcrlp inhibits development of fluconazole resistance in Candida albicans by abolishing CDR1 induction. Biol Pharm Bull 30: 68-73.

Shields RK, Nguyen MH, Du C, Press E, Cheng S, Clancy CJ. 2011. Paradoxical effect of caspofungin against Candida bloodstream isolates is mediated by multiple pathways but eliminated in human serum. Antimicrob Agents Chemother 55: 2641-2647.

Siikala E, Rautemaa R, Richardson M, Saxen H, Bowyer P, Sanglard D. 2010. Persistent Candida albicans colonization and molecular mechanisms of azole resistance in autoimmune polyendocrinopathy-candidiasis-ectodermal dystrophy (APECED) patients. J Antimicrob Chemother 65: 2505-2513.

Silva S, Henriques M, Martins A, Oliveira R, Williams D, Azeredo J. 2009. Biofilms of non-Candida albicans Candida species: Quantification, structure and matrix composition. Med Mycol 47: 681-689.
Silver PM, Oliver BG, White TC. 2004. Role of Candida albicans transcription factor Upc2p in drug resistance and sterol metabolism. Eukaryot Cell 3: 1391-1397.

Singh SD, Robbins N, Zaas AK, Schell WA, Perfect JR, Cowen LE. 2009. Hsp90 governs echinocandin resistance in the pathogenic yeast Candida albicans via calcineurin. PLoS Pathog 5: e1000532.

Singh-Babak SD, Babak T, Diezmann S, Hill JA, Xie JL, Chen YL, Poutanen SM, Rennie RP, Heitman J, Cowen LE. 2012. Global analysis of the evolution and mechanism of echinocandin resistance in Candida glabrata. PLoS Pathog 8: e1002718.

Sionov E, Lee H, Chang Y, Kwon-Chung K. 2010. Cryptococcus neoformans overcomes stress of azole drugs by formation of disomy in specific multiple chromosomes. PLoS Pathog 6: e1000848.

Sionov E, Chang YC, Garraffo HM, Dolan MA, Ghannoum MA, Kwon-Chung KJ. 2012. Identification of a Cryptococcus neoformans cytochrome P450 lanosterol $14 \alpha$ demethylase (Erg11) residue critical for differential susceptibility between fluconazole/voriconazole and itraconazole/posaconazole. Antimicrob Agents Chemother 56: $1162-1169$.

Sionov E, Chang YC, Kwon-Chung KJ. 2013. Azole heteroresistance in Cryptococcus neoformans: Emergence of resistant clones with chromosomal disomy in the mouse brain during fluconazole treatment. Antimicrob Agents Chemother 57: 5127-5130.

Slater JL, Howard SJ, Sharp A, Goodwin J, Gregson LM, Alastruey-Izquierdo A, Arendrup MC, Warn PA, Perlin DS, Hope WW. 2011. Disseminated candidiasis caused by Candida albicans with amino acid substitutions in Fks1 at position Ser645 cannot be successfully treated with micafungin. Antimicrob Agents Chemother 55: 3075-3083.

Slaven JW, Anderson MJ, Sanglard D, Dixon GK, Bille J, Roberts IS, Denning DW. 2002. Increased expression of a novel Aspergillus fumigatus $\mathrm{ABC}$ transporter gene, atrF, in the presence of itraconazole in an itraconazole resistant clinical isolate. Fungal Genet Biol 36: 199-206.

Snelders E, van der Lee HA, Kuijpers J, Rijs AJ, Varga J, Samson RA, Mellado E, Donders AR, Melchers WJ, Verweij PE. 2008. Emergence of azole resistance in Aspergillus fumigatus and spread of a single resistance mechanism. PLoS Med 5: e219.

Snelders E, Karawajczyk A, Schaftenaar G, Verweij PE, Melchers WJ. 2010. Azole resistance profile of amino acid changes in Aspergillus fumigatus CYP51A based on protein homology modeling. Antimicrob Agents Chemother 54: 2425-2430.

Snelders E, Camps SM, Karawajczyk A, Schaftenaar G, Kema GH, van der Lee HA, Klaassen CH, Melchers WJ, Verweij PE. 2012. Triazole fungicides can induce cross-resistance to medical triazoles in Aspergillus fumigatus. PLoS ONE 7: e31801.

Steinbach WJ, Reedy JL, Cramer RA Jr, Perfect JR, Heitman J. 2007. Harnessing calcineurin as a novel anti-infective agent against invasive fungal infections. Nat Rev Microbiol 5: 418-430.

Stevens DA, Espiritu M, Parmar R. 2004. Paradoxical effect of caspofungin: Reduced activity against Candida albi- 


\section{L.E. Cowen et al.}

cans at high drug concentrations. Antimicrob Agents Chemother 48: 3407-3411.

Sun N, Fonzi W, Chen H, She X, Zhang L, Zhang L, Calderone R. 2013. Azole susceptibility and transcriptome profiling in Candida albicans mitochondrial electron transport chain complex I mutants. Antimicrob Agents Chemother 57: 532-542.

Sussman A, Huss K, Chio LC, Heidler S, Shaw M, Ma D, Zhu G, Campbell RM, Park TS, Kulanthaivel P, et al. 2004. Discovery of cercosporamide, a known antifungal natural product, as a selective Pkcl kinase inhibitor through high-throughput screening. Eukaryot Cell 3: 932-943.

Taipale M, Jarosz DF, Lindquist S. 2010. HSP90 at the hub of protein homeostasis: Emerging mechanistic insights. Nat Rev Mol Cell Biol 11: 515-528.

Talibi D, Raymond M. 1999. Isolation of a putative Candida albicans transcriptional regulator involved in pleiotropic drug resistance by functional complementation of a $p d r 1$ pdr3 mutation in Saccharomyces cerevisiae. J Bacteriol 181: $231-240$.

Thakur JK, Arthanari H, Yang F, Pan S-J, Fan X, Breger J, Frueh DP, Gulshan K, Li DK, Mylonakis E, et al. 2008. A nuclear receptor-like pathway regulating multidrug resistance in fungi. Nature 452: 604-609.

Tobin MB, Peery RB, Skatrud PL. 1997. Genes encoding multiple drug resistance-like proteins in Aspergillus fumigatus and Aspergillus flavus. Gene 200: 11-23.

Torelli R, Posteraro B, Ferrari S, La Sorda M, Fadda G, Sanglard D, Sanguinetti M. 2008. The ATP-binding cassette transporter-encoding gene $C g S N Q 2$ is contributing to the CgPDR1-dependent azole resistance of Candida glabrata. Mol Microbiol 68: 186-201.

Tortorano AM, Prigitano A, Lazzarini C, Passera M, Deiana ML, Cavinato S, De Luca C, Grancini A, Lo Cascio G, Ossi C, et al. 2013. A 1-year prospective survey of candidemia in Italy and changing epidemiology over one decade. Infection 41: 655-662.

Tsai H, Krol A, Sarti K, Bennett J. 2006. Candida glabrata PDR1, a transcriptional regulator of a pleiotropic drug resistance network, mediates azole resistance in clinical isolates and petite mutants. Antimicrob Agents Chemother 50: 1384-1392.

Tsai HF, Sammons LR, Zhang X, Suffis SD, Su Q, Myers TG, Marr KA, Bennett JE. 2010. Microarray and molecular analyses of the azole resistance mechanism in Candida glabrata oropharyngeal isolates. Antimicrob Agents Chemother 54: 3308-3317.

Vandeputte P, Larcher G, Berges T, Renier G, Chabasse D, Bouchara JP. 2005. Mechanisms of azole resistance in a clinical isolate of Candida tropicalis. Antimicrob Agents Chemother 49: 4608-4615.

van der Linden JW, Snelders E, Kampinga GA, Rijnders BJ, Mattsson E, Debets-Ossenkopp YJ, Kuijper EJ, Van Tiel FH, Melchers WJ, Verweij PE. 2011. Clinical implications of azole resistance in Aspergillus fumigatus, The Netherlands, 2007-2009. Emerg Infect Dis 17: 1846-1854.

van der Linden JW, Camps SM, Kampinga GA, Arends JP, Debets-Ossenkopp YJ, Haas PJ, Rijnders BJ, Kuijper EJ, van Tiel FH, Varga J, et al. 2013. Aspergillosis due to voriconazole highly resistant Aspergillus fumigatus and recovery of genetically related resistant isolates from domiciles. Clin Infect Dis 57: 513-520.
Vermitsky J-P, Edlind TD. 2004. Azole resistance in Candida glabrata: Coordinate upregulation of multidrug transporters and evidence for a Pdr1-like transcription factor. Antimicrob Agents Chemother 48: 3773-3781.

Vermitsky J-P, Earhart KD, Smith WL, Homayouni R, Edlind TD, Rogers PD. 2006. Pdr1 regulates multidrug resistance in Candida glabrata: Gene disruption and genome-wide expression studies. Mol Microbiol 61: 704722.

Verweij PE, Mellado E, Melchers WJ. 2007. Multiple-triazole-resistant aspergillosis. $N$ Engl J Med 356: 14811483.

Verweij PE, Howard SJ, Melchers WJ, Denning DW. 2009. Azole-resistance in Aspergillus: Proposed nomenclature and breakpoints. Drug Resist Updat 12: 141-147.

Verweij PE, Kema GH, Zwaan B, Melchers WJ. 2013. Triazole fungicides and the selection of resistance to medical triazoles in the opportunistic mould Aspergillus fumigatus. Pest Manag Sci 69: 165-170.

Walker LA, Munro CA, de Bruijn I, Lenardon MD, McKinnon A, Gow NA. 2008. Stimulation of chitin synthesis rescues Candida albicans from echinocandins. PLoS Pathog 4: e1000040.

Walker LA, Gow NA, Munro CA. 2010. Fungal echinocandin resistance. Fungal Genet Biol 47: 117-126.

Walker LA, Gow NA, Munro CA. 2013. Elevated chitin content reduces the susceptibility of Candida species to caspofungin. Antimicrob Agents Chemother 57: 146-154.

Warnock DW. 2007. Trends in the epidemiology of invasive fungal infections. Nihon Ishinkin Gakkai Zasshi 48: 1-12.

White TC. 1997. Increased mRNA levels of ERG16, CDR, and MDR1 correlate with increases in azole resistance in Candida albicans isolates from a patient infected with human immunodeficiency virus. Antimicrob Agents Chemother 41: 1482-1487.

White TC, Marr KA, Bowden RA. 1998. Clinical, cellular, and molecular factors that contribute to antifungal drug resistance. Clin Microbiol Rev 11: 382-402.

White TC, Holleman S, Dy F, Mirels LF, Stevens DA. 2002. Resistance mechanisms in clinical isolates of Candida albicans. Antimicrob Agents Chemother 46: 1704-1713.

Wiederhold NP, Kontoyiannis DP, Prince RA, Lewis RE. 2005. Attenuation of the activity of caspofungin at high concentrations against Candida albicans: Possible role of cell wall integrity and calcineurin pathways. Antimicrob Agents Chemother 49: 5146-5148.

Wiederhold NP, Najvar LK, Bocanegra RA, Kirkpatrick WR, Patterson TF. 2011. Caspofungin dose escalation for in vasive candidiasis due to resistant Candida albicans. Antimicrob Agents Chemother 55: 3254-3260.

Xiao L, Madison V, Chau AS, Loebenberg D, Palermo RE, McNicholas PM. 2004. Three-dimensional models of wild-type and mutated forms of cytochrome P450 14 $\alpha$ sterol demethylases from Aspergillus fumigatus and Candida albicans provide insights into posaconazole binding. Antimicrob Agents Chemother 48: 568-574.

Znaidi S, Barker K, Weber S, Alarco A, Liu T, Boucher G, Rogers P, Raymond M. 2009. Identification of the Candida albicans Cap1p regulon. Eukaryot Cell 8: 806-820. 


\section{$\&_{\mathrm{CSH}}^{\infty} \&$ Cold Spring Harbor

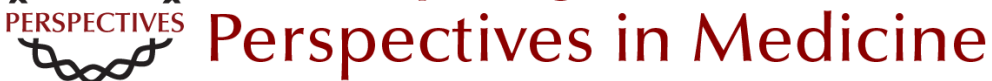

\section{Mechanisms of Antifungal Drug Resistance}

Leah E. Cowen, Dominique Sanglard, Susan J. Howard, P. David Rogers and David S. Perlin

Cold Spring Harb Perspect Med 2015; doi: 10.1101/cshperspect.a019752 originally published online November 10, 2014

\section{Subject Collection Human Fungal Pathogens}

\section{Evolutionary Perspectives on Human Fungal Pathogens John W. Taylor}

Black Molds and Melanized Yeasts Pathogenic to Humans Anuradha Chowdhary, John Perfect and G. Sybren de Hoog

Fungal Pathogens: Survival and Replication within Macrophages Andrew S. Gilbert, Robert T. Wheeler and Robin C. May

Innate Defense against Fungal Pathogens Rebecca A. Drummond, Sarah L. Gaffen, Amy G. Hise, et al.

Antifungal Pharmacokinetics and Pharmacodynamics Alexander J. Lepak and David R. Andes

Human Fungal Pathogens of Mucorales and Entomophthorales

Leonel Mendoza, Raquel Vilela, Kerstin Voelz, et al.

Functional Profiling of Human Fungal Pathogen Genomes

Alexi I. Goranov and Hiten D. Madhani

Aspergillus fumigatus and Related Species Janyce A. Sugui, Kyung J. Kwon-Chung, Praveen R. Juvvadi, et al.
Thermally Dimorphic Human Fungal Pathogens-Polyphyletic Pathogens with a Convergent

Pathogenicity Trait Anita Sil and Alex Andrianopoulos

Mechanisms of Antifungal Drug Resistance Leah E. Cowen, Dominique Sanglard, Susan J. Howard, et al.

Treatment Principles for Candida and Cryptococcus Laura C. Whitney and Tihana Bicanic

The Human Mycobiome Patrick C. Seed

Treatment Principles for the Management of Mold Infections

Dimitrios P. Kontoyiannis and Russell E. Lewis

Adaptive Immunity to Fungi Akash Verma, Marcel Wüthrich, George Deepe, et al.

The Candida Pathogenic Species Complex Siobhán A. Turner and Geraldine Butler

Fungal Morphogenesis Xiaorong Lin, J. Andrew Alspaugh, Haoping Liu, et al.

For additional articles in this collection, see http://perspectivesinmedicine.cshlp.org/cgi/collection/ 